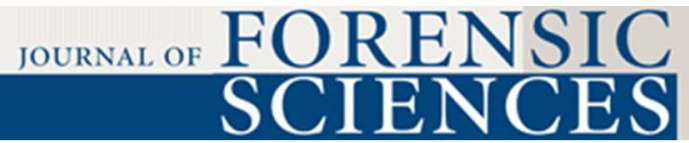

\title{
Long-term geophysical monitoring of simulated clandestine graves using electrical and Ground Penetrating Radar methods: 4-6 years after burial
}

\begin{tabular}{|r|l|}
\hline Journal: & Journal of Forensic Sciences \\
\hline Manuscript ID: & JOFS-14-567.R1 \\
\hline Manuscript Type: & Paper \\
\hline Date Submitted by the Author: & n/a \\
\hline Complete List of Authors: & $\begin{array}{l}\text { Pringle, Jamie; Keele University, School of Physical Sciences \& Geography } \\
\text { Jervis, John; Keele University, School of Physical Sciences \& Geography } \\
\text { Roberts, Daniel; Keele University, School of Physical Sciences \& Geography } \\
\text { Dick, Henry; Keele University, School of Physical Sciences \& Geography } \\
\text { Wisniewski, Kristopher; Keele University, School of Physical Sciences \& } \\
\text { Geography } \\
\text { Cassidy, Nigel; Keele University, School of Physical Sciences \& Geography } \\
\text { Cassella, John; Staffordshire University, Forensic Science }\end{array}$ \\
\hline Keywords: & $\begin{array}{l}\text { forensic science, forensic geophysics, clandestine grave, monitoring, } \\
\text { electrical resistivity, ground penetrating radar, conductivity }\end{array}$ \\
\hline
\end{tabular}

\section{SCHOLARONE}

Manuscripts 
Long-term geophysical monitoring of simulated clandestine graves using electrical and Ground Penetrating Radar methods: 4-6 years after burial

\section{3}

4 Jamie K. Pringle, ${ }^{1}$ Ph.D.; John R. Jervis, ${ }^{1,2}$ Ph.D.; Daniel Roberts, ${ }^{1}$ M.Sc.; Henry C.

5 Dick, ${ }^{1}$ B.Sc; Kris Wisniewski, ${ }^{1}$ B.Sc; Nigel J. Cassidy, ${ }^{1}$ Ph.D.; and John P. Cassella, ${ }^{3}$

6 Ph.D.

7

$8{ }^{1}$ School of Physical Sciences \& Geography, Keele University, Keele, Staffordshire

9 ST5 5BG, U.K.

$10 \quad{ }^{2}$ Exploration Electronics Ltd., London Road, Beccles, Suffolk, NR34 8TS, U.K.

$11{ }^{3}$ Department of Forensic and Crime Science, Staffordshire University, College Road, 12 Stoke-on-Trent, Staffordshire ST4 2DE, U.K.

13

14 Sources of funding:

15

16 A U.K. HEFCE SRIF2 equipment grant funded purchase of geophysical equipment. 17 


\section{ABSTRACT}

21 This ongoing monitoring study provides forensic search teams with systematic

22 geophysical data over simulated clandestine graves for comparison to active cases.

23 Simulated 'wrapped', 'naked' and 'control' burials were created. Multiple

24 geophysical surveys were collected over six-years, here showing data from four to six

25 years after burial. Electrical resistivity (twin electrode and ERI), multi-frequency

26 GPR, grave and background soilwater were collected. Resistivity surveys revealed

27 the naked burial had low-resistivity anomalies up to year four but then difficult to

28 image, whereas the wrapped burial had consistent large high-resistivity anomalies.

29 GPR 110-900 MHz frequency surveys showed the wrapped burial could be detected

30 throughout, but the naked burial was either not detectable or poorly resolved. 225

$31 \mathrm{MHz}$ frequency GPR data were optimal. Soil water analyses showed decreasing (year

32 four-five) to background (year six) conductivity values. Results suggest both

33 resistivity and GPR surveying if burial style unknown, with winter to spring surveys

34 optimal and increasingly important as time increases.

35

36 Keywords: forensic science; forensic geophysics; clandestine grave; monitoring;

37 electrical resistivity; ground penetrating radar; conductivity 
40 Forensic search methods vary widely, for example, in the UK a search strategist is

41 usually involved in a case at an early stage to decide upon the highest probability of

42

43

44

45

46

47

48

49

\section{0} search success [1], whereas in other countries a search may not be methodical, investigations may not be standardised and a variety of techniques are undertaken, depending upon local experience [2]. Metal detector search teams [3-5] and specially trained search dogs [5-7] are both commonly used during either initial investigations or as part of a phased sequential programme.

Forensic investigators have been increasingly using geoscientific methods to aid in civil or criminal forensic investigations, predominantly to assist search teams or for trace evidence purposes [8-11]. One key and high-profile 'target' for forensic search teams to detect and locate is human remains buried within clandestine graves $[1,5,12]$. These searches generally start from large-scale remote sensing methods [13-14], aerial and ultraviolet photography $[10,15]$, thermal imaging [16], to ground-based observations of vegetation changes [4], surface geomorphology changes [17], soil type [1] and depositional environment(s) [10], near-surface geophysics [11], diggability surveys [1] and probing of anomalous areas [18,19] before topsoil removal [4], and finally controlled excavation and recovery [5,15,20]. A typical search will only use a few of these techniques, depending on the circumstances of each case (Colin Hope, pers. comm.).

1 Near-surface geophysical methods rely on there being a detectable physical contrast between the target and the background (or host) materials (see [21]). Near-surface geophysical surveys have been used to try and locate clandestine graves in a number of reported criminal search investigations [3,5,22-32]. Geophysical surveys collected 
65 over simulated burials have been undertaken in order to collect control data (e.g. [33-

66 37]. These studies have shown that the resulting geophysical responses could be well

67

68

69 predicted, although responses seem to vary both temporally after burial and between different study sites. A few studies have also collected repeat (time-lapse) geophysical surveys over controlled experiments (e.g. [26,38-44]), which have documented temporal changes in geophysical responses over their study periods.

However, uncertainties still remain over what and how long temporal variations occur in geophysical surveys after burial, with study survey sites needing to be fully characterised (e.g. geologically and climatologically) to allow comparisons with other studies or indeed for active forensic cases. Documenting temporal changes is important as geophysical responses from recent clandestine burials are known to vary more than archaeological graves. Potential reasons for this could be the temporal changes in grave soil characteristics, decomposition products [45], climatic variations, soil moisture content [46] and other site specific factors (see [11]).

This study continued the systematic assessment of the changing geophysical response of simulated clandestine graves during four to six years after burial. Geophysical survey results from zero to three years after burial were published in [47]. A clandestine grave was defined in this study as an unrecorded burial that has been hand-excavated and dug $<1 \mathrm{~m}$ depth below ground level (bgl). It should be noted that geophysical results will vary depending upon the depth of burial and indeed on local soil type as [11] reviews. The discovered graves published in $[15,48]$ were usually rectangular in plan-view, mostly hurriedly hand dug using garden implements and usually just large enough to deposit the victim before being back-filled with excavated soil and associated surface debris. [48] also detailed that almost half of the 87 
90 documented U.S. cases were either clothed or encased in material (plastic or fabric),

91 so the authors decided to use two end member scenarios for this study; namely one burial containing a naked cadaver and another containing a cadaver wrapped in a tarpaulin. It is, however, emphasised that these obviously do not represent all types of potential style of burial with [42] considering other scenarios.

There are many potential near-surface geophysical search techniques that could be utilised to search for clandestine graves that the [47] monitoring paper summarises; this ongoing study has concentrated on collecting electrical resistivity (fixed-offset and Electrical Resistivity Imaging 2D profiles) and Ground Penetrating Radar (110 $900 \mathrm{MHz}$ frequency 2D profiles. Resistivity surveys showed consistent low anomalies, compared to background values, for a naked burial, in contrast with the wrapped burial which had smaller and varied low/high anomalies and was thus harder

103 to locate [47]. Analyses of decompositional fluids showed highest conductivity

104 values, compared to background soilwater, was $\sim 1$ year to $\sim 2$ years after burial before 105 subsequently decreasing [47]. GPR surveys finally showed low frequency antennae

106 were consistently optimal for target detection [47].

108 The aims of this continued four to six year geophysical monitoring study of different

109 simulated burial style clandestine burials were to answer some basic questions posed

110 by forensic search teams. Appropriate site data (rainfall, temperature, soil and 'grave'

111 water conductivities) were also continued to be simultaneously collected in order to

112 allow comparisons with other research studies and criminal search investigations.

113 Basic forensic search questions which were continued to be addressed by this study

114 were: 
115 A) Could twin electrode (fixed-offset) and electrical resistivity imaging surveys still

116 successfully locate both simulated clandestine burials beyond three years after

117 burial? And if so, how long were they geophysically detectable for?

118 B) Could single profile GPR surveys successfully locate both simulated clandestine

119 burials throughout the four to six year post-burial monitoring period? If this was

120 the case, which dominant frequency antenna was optimal to detect them?

121 C) When was the optimal time (both up to six years post-burial and seasonally) to

122 undertake a forensic GPR or electrical resistivity geophysical search survey?

123 D) When should a forensic geophysical survey be undertaken in a six year search $124 \quad$ scenario?

125 


\section{Methodology}

127

128 Study site

130 The chosen controlled test site was located on Keele University campus, $\sim 200 \mathrm{~m}$

131 above sea level, close to the town of Newcastle-under-Lyme in Staffordshire, UK.

132 The local climate is temperate, which is typical for the UK [49]. The study site was a

133 grassed, small rectangular area $(\sim 25 \mathrm{~m} \mathrm{x} \sim 25 \mathrm{~m})$, surrounded by small deciduous trees

134 (Fig. 1). The geophysical survey area measured $5 \mathrm{~m} \mathrm{x} 14 \mathrm{~m}$ and sloped by

135 approximately $3^{\circ}$ from northwest to southeast. Within this area were the 'naked pig'

136 grave, the empty grave and the 'wrapped pig' grave emplaced in sandy loam soil (Fig.

137 1). [47] provides other relevant background site information.

138

139 The test site was located $200 \mathrm{~m}$ from the Keele University weather observation

140 station, which continually measured daily rainfall and air and ground temperatures as

141 well as having soil temperature probes at $0.1 \mathrm{~m}, 0.3 \mathrm{~m}$ and $1.0 \mathrm{~m}$ below ground level.

142 Figure 2 shows a monthly summary of the total rainfall and average temperature data

143 over the monitoring period with temperature data for the zero to three year monitoring

144 study also shown for comparison. The local weather station data showed that total

145 monthly rainfall during the four to six year study period ranged from $2.6 \mathrm{~mm}$ to 152.2

$146 \mathrm{~mm}$, with an overall monthly average of $64.7 \mathrm{~mm}$, the same as for the zero to three

147 year monitoring period [47]. Average monthly air temperatures ranged from $-1.2{ }^{\circ} \mathrm{C}$

148 to $12.8{ }^{\circ} \mathrm{C}$, with an overall monthly average of $5.5^{\circ} \mathrm{C}, 3.2{ }^{\circ} \mathrm{C}$ colder than for the zero

149 to three year monitoring period (Fig. 2). However, note at $0.3 \mathrm{~m}$ bgl the average

150 temperature was $10.2^{\circ} \mathrm{C}$ for the four to six year monitoring period and $9.8^{\circ} \mathrm{C}$ for the 
151 0-3 year monitoring period [47]. Accumulated Degree Day (ADD) data (see [50] for

152 background) detailed in Table 1 quantified these temperature differences.

153

154 FIG. 1. -position

155

156 FIG. 2. -position

157

158 Simulated graves

159

160 Five simulated graves were created at the site (Fig. 1A). Three of the graves were

161 used for the repeat geophysical surveys, whilst ground water samples were collected

162 at regular intervals from both the fourth grave and a separate control site situated $\sim 10$

163 m upslope away from the graves (Fig. 1E-F), both of the soilwater sampling sites

164 being outside the geophysical survey area (Fig. 1A). Of the three simulated graves

165 geophysically surveyed, one contained a naked pig carcass, one contained a carcass

166 wrapped in woven PVC tarpaulin and the third was an empty grave to act as a control

167 (Fig. 1). Pig cadavers are commonly used in such monitoring experiments as they

168 comprise similar chemical compositions, size, tissue:body fat ratios and skin/hair type

169 to humans [51,52]. The grave emplacement procedure was described in [47].

170

171 Bulk ground water conductivity data collection

172

173 Ground water sample lysimeters were emplaced both within a grave containing a pig

174 carcass outside the geophysical survey area and a further lysimeter $\sim 10 \mathrm{~m}$ from the

175 survey area to act as control (Fig. 1). The lysimeter emplacement and regular sample 
176 collection (Table 1) and analysis procedures used in this study were the same as for

177 the initial three year monitoring period and are described in [47]. The only change

178 was the sample frequency with samples collected at approximately three-monthly

179 seasonal intervals during the four to six year monitoring period due to limited monthly

180 changes observed in the zero to three year monitoring period [47] and survey time

181 constraints (Table 1).

182

183 TABLE 1.

184

185 Near surface geophysical data collection \& processing 186

187 Twin electrode ( $0.5 \mathrm{~m}$ fixed-offset) resistivity surveys were conducted at three

188 monthly intervals over the geophysical survey area (Fig. 1A-B) during the four to six

189 year monitoring period (Table 1). Data was collected using the RM15 (Geoscan ${ }^{\mathrm{TM}}$

190 Research) resistivity meter on a $0.25 \mathrm{~m}$ by $0.25 \mathrm{~m}$ grid with remote probes placed on

191 the same position $17 \mathrm{~m}$ from the survey area for consistency. Subsequent data

192 processing methodology was the same as detailed in [47].

193

194 A 2D Electrical Resistivity Imaging (ERI) survey line orientated SW-NE (Fig. 1A-B)

195 was surveyed at approximately three-monthly intervals (Table 1). 32 electrodes were

196 placed every $0.5 \mathrm{~m}$ along the $15.5 \mathrm{~m}$ long survey profile that bisected all three graves

197 (Fig. 1A). Geophysical survey collection using a Campus ${ }^{\text {TM }}$ TIGRE system and

198 subsequent inversion using Geotomo ${ }^{\mathrm{TM}}$ Res2Dinv v.355 software used in this study

199 were the same as for the initial three year monitoring period and are described in [47].

200 
201 Due to the variable results of horizontal time slices that GPR data generated in the 202 zero to three year monitoring survey period (see [47]), 2D GPR profiles were only 203 collected on two profiles within the survey area that bisected the two simulated graves 204 with pigs present (Fig. 1A) at approximately three-monthly intervals (Table 1). GPR 205 data collection using the PulseEKKO ${ }^{\text {TM }} 1000$ equipment utilised $110 \mathrm{MHz}, 225 \mathrm{MHz}$, $206450 \mathrm{MHz}$ and $900 \mathrm{MHz}$ dominant frequency antennae, with radar trace spacings being $2070.2 \mathrm{~m}, 0.1 \mathrm{~m}, 0.05 \mathrm{~m}$, and $0.025 \mathrm{~m}$, respectively, using 32 "stacks" to increase the 208 signal-to-noise ratio and for all data sets for consistency purposes. Subsequent data 209 processing were the same as for the initial three year monitoring period and are 210 described in [47].

211

212 


\section{Results}

214

215 Table 1 qualitatively summarises the respective geophysical anomaly visibilities in

216 survey results based on [42] methodology of: None, Poor, Good and Excellent. A

217 score of None indicated the respective grave was not detected, with a score of Poor

218 showed a slightly discernible geophysical anomaly at the grave location. A score of

219 Good demonstrates a clear geophysical anomaly that would be discernible in the field

220 during a geophysical survey and a score of Excellent demonstrates a clearly

221 discernible and prominent anomaly at the grave location.

222

223

Bulk ground water conductivity

224

225

226

227

228

229

230

231

232

233

234

Background soilwater conductivity measurements demonstrated that background values were consistent over the three year monitoring period (averaging $355 \pm 0.1$ $\mu \mathrm{S} / \mathrm{cm}$ with $40 \mathrm{SD}$ ) that was comparable to the zero to three year monitoring period (averaging $444 \pm 0.1 \mu \mathrm{S} / \mathrm{cm}$ ). However, the pig leachate conductivity continued to reduce during year four (Fig. 3A), varying from $6,670 \pm 0.1 \mu \mathrm{S} / \mathrm{cm}(1,099$ days after burial) down to consistent and comparable background values of $356 \pm 0.1 \mu \mathrm{S} / \mathrm{cm}$ after 1,670 days of burial to the end of the monitoring period. Pig leachate conductivity changes during the first three years of burial are reported in [47]. Leachate values in this study could be divided into two clear groupings of conductivity against post-burial days; $840-1,670$ burial days (which included some 235 data from the third year of monitoring) and 1,670 burial days to the end of the survey 236 period respectively (Fig. 3A). The first data grouping had a decreasing regression line 237 against burial days with a reasonable fit $\left(\mathrm{R}^{2}=0.88\right)$, with the second data grouping 
238 having a flat regression line, albeit with a relatively poor correlation $\left(\mathrm{R}^{2}=0.47\right)$ due

239 to its flat nature, evidencing that pig leachate conductivity was consistently at

240 background soilwater values (Fig. 3A).

241

242

\section{FIG. 3. - position}

243

244 Site temperature variation could be removed from raw conductivity values as

245 discussed in [47 Pringle et al. 2012 jfs] by weighting each day by its average daily

246 temperature and then giving each day after burial an accumulated degree day (ADD)

247 following standard methods [50]. This study still had the advantage of having

248 temperature probe measurement data available from the actual mid-cadaver depth

$249(\sim 0.3 \mathrm{~m} \mathrm{bgl})$ from the nearby meteorological weather station, instead of using average

250 air temperatures (Fig. 2). This again allowed the separation of two data groupings

251 with two linear regression correlations to be generated of conductivity against ADD,

252 with similar fits to those generated against post-burial days $\left(\mathrm{R}^{2}\right.$ values of 0.86 and

2530.57 respectively), see Fig. 3B.

254

255 Twin electrode (fixed-offset) resistivity

256

257 Bulk ground resistivity surveys acquired over the four to six year monitoring study

258 period were again remarkably consistent, with average fixed-offset survey resistance

259 values of $63.6 \Omega$ (with $47.0 \Omega$ minimum and $99.4 \Omega$ maximum values respectively)

260 (compared to an average of $67.1 \Omega$ for zero to three years), after de-spiking data (only

261 averaged 1.6 anomalous 'spike' per survey). The three monthly processed fixed- 
262 offset resistivity surveys are graphically shown in Figure 4 (see Fig. 1A for 'grave'

263 locations) and summarised in Table 1.

264

265 As found in the zero to three year monitoring datasets, the empty grave which acted as 266 control could not be geophysically detected throughout the survey period (green boxes 267 in Fig. 4). The naked pig grave (red boxes in Fig. 4) was anomalously temporally 268 variable throughout the four to six year monitoring period, mostly comprising a small $269\left(<0.6 \mathrm{~m}^{2} \mathrm{SD}\right)$ amplitude mixed low/high anomaly, when compared to background 270 values (Fig. 4 and Table 1). It only comprised a large anomaly with a low resistivity 271 (coloured blue) in the winter Year 4 dataset that was consistently observed in the zero 272 to three year monitoring datasets (see [40] and Table 1). In contrast, the wrapped pig 273 grave (blue boxes in Fig. 4) showed predominantly a large ( $>0.6 \mathrm{~m}^{2} \mathrm{SD}$ ) amplitude 274 high resistivity anomaly (coloured red/white), when compared to background values, 275 that was mostly Good to Excellent rating and appeared to have increased in size from 276 the zero to three year monitoring dataset immediately after burial (see [47] and Table 277 1).

278

279 FIG. 4. - position

280

281 Electrical resistivity imaging (ERI)

282

283 After de-spiking data, electrical resistivity imaging surveys acquired over the four to 284 six year monitoring study period were also again consistent, with average ERI six ' $n$ ' 285 level survey resistivity values of $197.0 \Omega . \mathrm{m}$ with $106.0 \Omega . \mathrm{m}$ minimum and $318.9 \Omega . \mathrm{m}$ 286 maximum respectively (compared to an average of $161.8 \Omega$ for zero to three years) A 
287 summary of the 2D ERI profiles collected is graphically shown in Figure 5 (see Fig.

288 1A for profile location) and summarised in Table 1. An average inversion model

289 error (RMS) of 2.1 (with 1.2 minimum and 5.1 maximum) after five iterations again

290 indicated a very good model inversion fit to the collected resistivity values (compared

291 to a RMS of 2.82 for zero to three years),

292

293 The empty grave (marked in Fig. 5) again could be detected throughout the survey

294 period, although, in contrast to the zero to three year monitoring period, it had

295 consistently higher resistivity values, when compared to neighbouring regions (Fig.

296 5). The naked pig grave was again generally detectable as a consistent Good rated

297 anomalous low, when compared to background values up to the end of year five,

298 although thereafter it was difficult to resolve from neighbouring regions (Fig. 5 and

299 Table 1). The wrapped pig grave was surprisingly detectable as a large high Good

300 rated resistivity anomaly, when compared to background values, although the

301 anomaly was relatively smaller in the summer and autumn of year's four and five

302 (Fig. 5). In the zero to three year monitoring survey the high resistivity anomaly was

303 relatively smaller (see [47] and Table 1).

304

305

FIG. 5. - position

306

307 Ground Penetrating Radar (GPR)

308

309 The 2D GPR profiles acquired throughout the four to six year monitoring survey

310 period are shown in Figure 6A and 6B (see Fig. 1A for profile locations) and

311 summarised in Table 1. The $110 \mathrm{MHz}$ dominant frequency 2D profiles showed the 
312 wrapped pig grave could still be consistently and clearly identified by a strong Good

313 to Excellent rated hyperbola throughout the survey period (except for year 5 summer),

314 although there was a continual reduction in reflection amplitudes. This was in

315 contrast to the naked pig grave which was either not detectable or at best produced a

316 Poor rated hyperbola throughout the survey period (see Fig.6A and 6B and Table 1).

317 There were no clear hyperbolae other than those associated with the target graves

318 within these $2 \mathrm{D}$ profiles.

320 The $225 \mathrm{MHz}$ dominant frequency 2D profiles still showed the wrapped pig grave

321 could be clearly identified by an obvious Good to Excellent rated hyperbola

322 throughout the four to six year monitoring survey period, although there was also a

323 continual reduction in reflection amplitudes (see Fig.6A and 6B). The second,

324 slightly deeper reflector that was first resolved after 15 months of burial within the

325 wrapped pig grave (see [47]) was still present in this dataset. The naked pig grave

326 was given a Poor to None rating of hyperbola anomaly throughout the four to six year

327 monitoring survey period although it was possible to detect in the autumn and winter

328 data of year 4 (Fig. 6A/B). As per the zero to three year monitoring survey results

329 [47], there were other, smaller hyperbolae present in the naked pig profiles that were

330 not associated with the target. This would have made it difficult to identify the target

331 grave if the position was not known. However, note they may have been detected if

332 data were collected orthogonally to the primary survey line orientation or indeed if

333 time slices were generated (although the zero to three year survey time slice data

334 detailed in [47] was poor). 
336 The $450 \mathrm{MHz}$ dominant frequency 2D profiles showed the wrapped pig grave could

337 be identified by a Good to Excellent rated hyperbola throughout the four to six year

338 monitoring survey period, but this had a consistently low amplitude (see Fig.6A and

339 6B and Table 1). The second, slightly deeper hyperbola observed after 3 months of

340 burial was still present during this survey period. The naked pig grave was rated as

341 Poor to None rated detectable as a hyperbola throughout the four to six year

342 monitoring period. There were again numerous other, smaller hyperbolae present in

343 both profiles that were not associated with the target grave which would have made it

344 difficult to identify the target grave if the position was not known. These may, again

345 have been detected if data were collected orthogonally to the primary survey line

346 orientation or indeed if time slices were generated (although the zero to three year

347 survey time slice data detailed in [47] was again poor).

348

349 The $900 \mathrm{MHz}$ dominant frequency 2D profiles was rated Poor to None rated so was

350 difficult to identify the naked pig grave throughout the four to six year monitoring

351 period (see Fig.6A and 6B). There were numerous other, smaller hyperbolae present

352 which would also have made it difficult to locate the target grave, although orthogonal

353 surveys may have been successful.

354

355 FIG. 6(A).

356

357 FIG. 6(B).

358

359

360 


\section{Discussion}

362

363 This study is the first published research to systematically detail resistivity, GPR and

364 site monitoring data over a simulated clandestine grave test site over six years of

365 burial summarised in Table 1. Importantly both naked and wrapped cadavers have

366 been emplaced and surveyed which provides the two main burial styles encountered

367 in discovered clandestine graves of murder victims. This has allowed questions by

368 forensic search teams listed in the introduction to be answered that has not been able

369 to be undertaken to date. These will be sequentially discussed and are deliberately

370 similar to those posed in the zero to three year monitoring paper [47].

A) Could twin electrode (fixed-offset) and electrical resistivity imaging surveys still

373 successfully locate the 'naked' and 'wrapped' simulated clandestine burials beyond

374 three years after burial? And if so, how long were they geophysically detectable for?

375 From the results of this long-term study, the answer was, it still depends on the burial

376 style. The fixed-offset electrical resistivity surveys showed that a naked cadaver(s)

377 has a good chance of being located up to 2.5 years after burial (see Table 1 and [47]),

378 due to the highly conductive grave fluid' producing a consistent low resistance

379 geophysical anomaly when compared to background site resistance values (Fig. 3).

380 This agrees with other resistivity studies over simulated clandestine burials with

381 similar monitoring time periods (see [26,52]. Recent collaborative research

382 comparing the same monitoring experiment on three different University sites in

383 contrasting soil types has evidenced that conductivity measurements of grave fluids

384 could date the burial interval of a discovered clandestine grave in the field if a

385 conductivity meter was available and enough grave fluid was present (see [45]). 
386 However, this study showed that a naked cadaver would be very difficult to detect

387 using fixed-offset electrical resistivity surveys after only four years of burial (Fig. 4)

388 and using ERI surveys after five years of burial (Fig. 5) respectively. The majority of

389 the grave fluids (other than that held by capillary pressure) would migrate away from

390 the cadaver and potentially result in a geophysical anomaly not being over the target,

391 and hence the subsequent search excavation team not finding the target, which would

392 be especially problematic in surveys within significant topographic variation (see

$393[1,30]$. In contrast, the wrapped or clothed cadaver(s) essentially largely isolated the

394 target and its conductive grave fluids from the surrounding soil, giving a potential

395 barrier to electrical current. There was therefore a small and temporally varying high

396 resistance anomaly, with respect to background site resistance values, identified over

397 the wrapped target location in the zero to three year monitoring data (see [47]), the

398 varying nature suggested to be caused by some leaking of grave fluids into the

399 surrounding soil. However, this paper detailing the four to six year monitoring data

400 showed a consistent large high resistance anomaly, when compared to background

401 site resistance values, to be present in both the fixed-offset and ERI electrical

402 resistivity datasets over the wrapped cadaver (see Figs. 4 and 5), this consistency

403 presumably due to most grave fluid at this time period being largely absent from the

404 survey area. Note that wrapping a body in plastic or clothing has also been reported

405 by others to slow decomposition [53] and inhibit micro-organism activity [51] which

406 therefore suggests a clandestinely buried body may be identifiable for longer if

407 wrapped in woven PVC tarpaulin as compared to naked.

408

409 Using all the resistivity datasets collected in the six year monitoring period, a

410 graphical time-line diagram has been generated to show temporal resistivity anomaly 
411 variations (Fig. 7). In terms of optimally configuring fixed-offset resistivity

412 equipment if the likely depth of burial is unknown, modern versions (eg. the

413 Geoscan ${ }^{\mathrm{TM}} \mathrm{RM}-15$ used in this study) have the capability to collect and digitally

414 record fixed-offset resistivity data at a variety of probe spacings almost

415 simultaneously at each sampling position (see [54] for forensic resistivity dataset

416 examples). This would therefore not significantly add to survey time if more than one

417 probe spacing data is collected and trace sample spacing could still be comparatively

418 small so that any potential loss in resolution is minimised. The forensic resistivity

419 sulvey results in this paper are in sandy loam soil, with good forensic resistivity

420 survey results also reported in coastal sand [36], chalky [26] and black earth [54] soil

421 types respectively, but relatively poor results in coarse pebble soil types [54].

422

424

425

426

427

428

429

430

431

432

433

434

435

\section{FIG. 7. - position}

\section{B)Could single profile GPR surveys successfully locate both simulated clandestine} burials throughout the four to six year monitoring period? And which dominant

frequency antenna was optimal to detect them? From the results shown in this four to six year monitoring study, the naked cadaver was not able to be detected on 2D GPR transverse profiles using either the $110 \mathrm{MHz}$ or $900 \mathrm{MHz}$ dominant frequency antennae and was only poorly detectable by the $225 \mathrm{MHz}$ dominant frequency antennae in the autumn to winter datasets (Fig. 6A/B). This was in contrast to the zero to three year monitoring period [47] and other studies undertaken on [47] timescale (e.g. see $[38,39,42])$. The naked cadaver, however, was detectable as a deeper $1 / 2$ hyperbolic reflection event in the $450 \mathrm{MHz} 2 \mathrm{D}$ transverse profiles although this did not have high amplitudes (Fig. 6A/B). In contrast, the wrapped cadaver was 
436 detectable on 2D GPR profiles using all the frequencies trialled, namely the 110,225

437 and $450 \mathrm{MHz}$ dominant frequency antennae (the $900 \mathrm{MHz}$ antennae was not used

438 over this grave, but it is believed that the grave could have been detected with this

439 frequency based on the other frequency data). This was presumably still due to the

440 wrapping surface allowing stronger GPR reflections to be obtained, with the

441 decomposing naked cadaver attenuating a greater proportion of the GPR signal as

442 other authors have noted (e.g. see [42]). This radar absorption would be exacerbated

443 by the pig-chest cavity having collapsed during decomposition stages as noted in [47],

444 which is a probable explanation for the two GPR hyperbolae still present in 225 and

$445450 \mathrm{MHz}$ dominant frequency data over the target location (Fig. 6A/B). $225 \mathrm{MHz}$

446 dominant frequency antennae was shown in this study to be preferable to the other

447 frequencies trialled (110, 450 and $900 \mathrm{MHz}$ frequencies) in the $2 \mathrm{D}$ profiles due to a

448 detectable anomaly, target resolution and fewer non-target hyperbolae present in the

449 relative higher frequency data; note also forensic $225 \mathrm{MHz}$ frequency radar surveys

450 also took less time in the field to acquire when compared to their higher frequency

451 versions. This could be an important factor for a forensic search team to consider if

452 the proposed area is significant in size or if manpower and/or budget are limited. This

453 agrees with others (e.g. [42]) who also suggested that 2D GPR profiles should be

454 collected in both orientations over a survey site if possible to have the best chance of

455 detection.

456

457 C) When was the optimal time (both up to six years post-burial and seasonally) to

458 undertake a forensic GPR or electrical resistivity geophysical search survey? Clearly

459 from the results shown in this study and others (e.g. [42]) the burial style is key, it

460 would be difficult to detect a naked burial after the first 18 months of burial using the 
461 resistivity and GPR survey methods detailed here and in [47]. However, note that

462 other studies have shown favourable GPR survey results over much older burials in

463 different ground conditions (eg. ([3,34,54,55]). Whilst there is a general reduction in

464 hyperbola quality in both burial styles, with the naked cadaver being much more

465 difficult to detect, there is a seasonal effect, with autumn and winter surveys,

466 especially in years four to six post burial, generally better at resolving the targets.

467 This has also been observed by authors geophysically monitoring simulated

468 clandestine burials on shorter time scales (e.g. [42]).

469

470 The resistivity surveys also showed a similar pattern, especially the fixed-offset

471 electrical resistivity surveys which, when following [46] methodology to numerically

472 measure resistivity anomaly relative areas over time, consistently showed winter

473 surveys were optimal (Table 1). Each autumn to winter the anomalies over both the

474 naked and wrapped cadavers increased in area and reduced in normalised standard

475 deviation (SD) values whereas they were comparably smaller and had larger SD

476 values in the summer months (Fig. 8). The naked cadaver's anomaly and the

477 normalised SD of the datasets got progressively smaller over time, but the wrapped

478 cadaver's relatively high resistance anomaly increased in size over the six year study

479 period (Fig. 8). Temporally varying resistivity anomalies over fixed archaeological

480 targets have also been reported by [56] who undertook time-lapse resistivity surveys

481 over UK Roman fortification defence ditches. This study therefore shows the cyclical

482 nature of low winter/spring SD values and high summer/autumn SD values repeating

483 each year that was most probably due to the soil having reduced moisture content

484 during the warmer and dryer periods but, importantly, in a non-uniform manner for

485 this study site. Thus the 'noise' present within the geophysical data significantly 
486 increased during these seasonal periods and effectively 'masked' the target(s). See

487 ([52] and [57] for detailed analysis of site soil moisture for the first two years of

488 burial.

489

490

FIG. 8. - position

491

492

D) When should a forensic geophysical survey be undertaken in a six year search

493 scenario? From this and other studies (e.g. 38-42,44]), clearly the burial style is still

494 key; although the wrapped grave was initially harder to detect with electrical

495 resistivity surveys (as shown in [47]), in this paper it is relatively easier to detect after

496 four to six years of burial (Fig. 7). The wrapping also makes the target easier to find

497 with GPR as the wrapping makes a good reflective target (Table 1). So although

498 wrapping may help to conceal a body in some ways (for example, it may trap scent

499 and prevent decompositional fluids leaching into the soil), it may also make a body

500 easier to find geophysically. If the burial style is not known, then it is suggested that

501 both electrical and GPR surveys be undertaken to have the best chance of successful

502 detection. Note a naked cadaver would be progressively more difficult to find after 18

503 months of burial as shown in this (Table 1) and other studies (see $[38-42,44]$ ), and

504 therefore other complementary methods should be trialled (e.g. search cadaver dogs).

505

506 This study also reinforces other research (see e.g. 38-42,44,56]) the importance of

507 when a forensic geophysical survey should be conducted within the year, seasonality

508 has shown to be surprisingly important, and, if operational time permits, then

509 geophysical surveys should be undertaken in winter to have the best chance of target

510 detection success. If a past forensic geophysical search was unsuccessful, perhaps the 
511 results should be reviewed in terms of seasonality and perhaps re-surveyed if the

512 original survey season was unfavourable. If there is a time-restricted element to the

513 forensic search, then the season of surveying should be undertaken and an appropriate

514 alternative search method should be chosen if necessary.

515

516 From this long-term simulated grave monitoring study and comparing results from

517 [24,27],29,38-42, 44,57-60], we still recommend that forensic geophysical surveys

518 should be undertaken prior to other, more invasive search methods (e.g. metal

519 detectors, soil/methane probes and cadaver dog probes). Any resulting soil

520 disturbances from these surveys would lead to more false positives for the resulting

521 geophysical surveys, as found during the [29] forensic resistivity search. Once

522 anomalous geophysical areas within the survey area are identified, these should be

523 prioritised and then subjected to more detailed scientific investigations, which

524 includes geophysical surveys (e.g. 2D ERI profiles, higher frequency 2D/3D GPR

525 surveys), cadaver dogs, invasive probing, etc. See [11] for other geoscience search

526 methods and suggested phased investigative approaches. 
529

530

531

532

533

534

535

536

537

538

539

540

541

542

543

544

545

546

547

548

549

550

551

552

553

\section{Conclusions and further work}

Geophysical long-term monitoring survey results over the simulated clandestine burials shown in this study and by others in different soil types should be used both to assist forensic search investigators to use the appropriate search technique and equipment configuration, and indeed as a reference to allow comparison of data collected by forensic search investigators looking for similar clandestine burials of murder victims.

A buried 'naked' victim within a clandestine burial, if shallowly buried, should be able to be located within the first 4 years of burial using twin electrode electrical resistivity surveys. If the burial depth is unknown, the use of wider electrode separations in addition to the most frequently used $0.5 \mathrm{~m}$ spacing is recommended. Resistivity surveys are also recommended to be undertaken in clay-rich soils over GPR surveys due to the likelihood of highly conductive 'leachate' being retained in the surrounding soil and GPR experiencing poor penetration depths in these soil types. However after this time period a naked victim would become progressively more difficult to locate using electrical methods, with the majority of the decompositional fluids migrating away from the target, depending upon the soil type. However, ERI 2D profiles could potentially still locate naked victims up to five years of burial if sited over it. $110-225 \mathrm{MHz}$ dominant frequency GPR surveys could detect targets well up to 18 months of burial, then $225 \mathrm{MHz}$ frequency poorly in winter months up to five years of burial due to decomposition, although skeletal material may still be imaged depending on target(s) depth and specific site conditions. If time and manpower availability permits then winter surveys should be undertaken. 
555 A buried 'wrapped' or clothed victim within a clandestine burial, if shallowly buried,

556 should be able to be located using both fixed-offset electrical resistivity and ERI 2D

557 Profile surveys throughout the six year monitoring period; in fact in this study it

558 became progressively easier to detect the wrapped cadaver as the burial period

559 extended. Medium (225-450 MHz) dominant frequency GPR antennae were deemed

560 optimal frequency for detection due to good target resolution as other authors have

561 evidenced (e.g. [41-42]); less non-target anomalies and data acquisition speed,

562 although $110 \mathrm{MHz}$ and $450 \mathrm{MHz}$ frequency antennae data also resolved the wrapped

563 grave throughout the study period, most probably due to the 'wrapping' producing a

564 good reflective contrast. If time and manpower availability permits then winter

565 surveys should be undertaken.

566

567 This study site will be continued to be monitored annually to discover at what time

568 period after burial will geophysical surveys not be able to determine the location of a

569 clandestine burial. Organic, inorganic and other analytical measurements are

570 currently being undertaken to examine what may be causing the variability in grave

571 'soilwater' conductivity after burial with preliminary results looking promising [61].

572

573 Further analysis of the geophysical data will also be undertaken; both to determine if

574 there are diagnostic GPR signal spectra for clandestine burials versus background

575 signals and to determine if both GPR and resistivity datasets can be simultaneously

576 inverted numerically to quantify anomaly location(s), sizes and to quantitatively

577 combine these two geophysical search techniques.

578 
579 This experimental methodology should be repeated on similar time scale in other,

580 contrasting soil types, in order to determine if soil type is a major factor in the ability

581 of forensic geophysical surveys to successfully locate a clandestine burial. On a

582 longer time scale, it is planned that the experiment will be repeated using human

583 cadavers rather than pig analogues, as this may be an important variable to consider.

584

585 
586 Acknowledgements

587

588 We acknowledge ex-Keele PhD student Tim Millington and Keele University

589 technical staff Malcolm Wright for assistance in creating the study site and Ian

590 Wilshaw for assistance in installing the lysimeters and providing local weather data.

591 Numerous Keele University undergraduate and postgraduate students assisted in

592 collecting geophysical data during this study, together with Giulia di Mascio from

593 Polimi University, Italy. Colin Hope of the U.K. National Crime Agency (NCA) is

594 thanked for operational search advice.

595 
596 References:

597

598 1. Harrison M, Donnelly LJ. Locating concealed homicide victims: developing the 599 role of geoforensics. In: Ritz K, Dawson L, Miller D, editors. Criminal and

600 Environmental Soil Forensics, Dordrecht: Springer, 2009;197-219.

601

602 2. Larson DO, Vass A A, Wise M. Advanced scientific methods and procedures in the

603 forensic investigation of clandestine graves. J Contemp Crim Justice 27 2011;27:149-

60482.

605

606 3. Davenport GC. Remote sensing applications in forensic investigations. Hist Arch $607 \quad 2001 ; 35: 87-100$.

608

609 4. Killam EW. The detection of human remains. Springfield: Charles C Thomas, 6102004.

611

612 5. Dupras TL, Schultz JJ, Wheeler SM, Williams LJ. Forensic recovery of human

613 remains: archaeological approaches. 2nd ed, Boca Raton, FL: CRC Press, 2011. 614

615 6. Rebmann A, David E, Sorg MH. Cadaver dog handbook: forensic training and 616 tactics for the recovery of human remains. Boca Raton:CRC Press, 2000. 
618 7. Lasseter A, Jacobi KP, Farley R, Hensel L. Cadaver dog and handler team

619 capabilities in the recovery of buried human remains in the Southeastern United

620 States. J For Sci 2003;48:1-5.

621

622 8. Pye K, Croft, DJ. Forensic Geoscience: Principles, Techniques and Applications.

623 London: Geol Soc London Spec Pub 232, 2004.

624

625 9. Ruffell A, McKinley J. Forensic geoscience: applications of geology,

626 geomorphology and geophysics to criminal investigations. Earth Sci Rev

$627 \quad 2005 ; 69: 235-47$.

628

629 10. Ruffell A, McKinley J. Geoforensics. Chichester: Wiley, 2008.

630

631 11. Pringle JK, Ruffell A, Jervis JR, Donnelly L, McKinley J, Hansen J, Morgan R,

632 Pirrie D, Harrison M. The use of geoscience methods for terrestrial forensic searches.

633 Earth Sci Rev 2012a;114:108-23.

634

635 12. Davenport GC, Griffin TJ, Lindemann JW, Heimmer D. Geoscientists and law

636 enforcement officers work together in Colorado. Geotimes 1990;35:13-5.

637

638 13. Brilis GM, Gerlach CL, van Waasbergen RJ. Remote sensing tools assist in

639 environmental forensics. Part I. Digital tools - traditional methods. Env For

$640 \quad 2000 \mathrm{a} ; 1: 63-7$.

641 
642 14. Brilis GM, van Waasbergen RJ, Stokely PM, Gerlach CL. Remote sensing tools

643 assist in environmental forensics. Part II. Digital tools. Env For 2000b;1:1-7.

644

645 15. Hunter J, Cox M. Forensic archaeology: advances in theory and practice.

646 Abingdon: Routledge, 2005.

647

648 16. Dickinson DJ. The aerial use of an infrared camera in a police search for the body

649 of a missing person in New Zealand. J For Sci Soc 1976;16:205-11.

650

651 17. Ruffell A, McKinley J. Forensic geomorphology. Geomorph 2014;206:14-22.

652

653 18. Owsley DW. Techniques for locating burials, with emphasis on the probe. J For

654 Sci 1995;40;735-40.

655

656 19. Ruffell A. Burial location using cheap and reliable quantitative probe

657 measurements. For Sci Int 2005a;151:207-11.

658

659 20. Hunter J, Simpson B, Sturdy Colls C, Forensic approaches to buried remains

660 (essential forensic science). Chichester: Wiley, 2013.

661

662 21. Reynolds JM. An introduction to applied and environmental geophysics, 2nd ed,

663 Chichester: Wiley-Blackwell, 2011.

664 
665 22. Mellet JS. Location of human remains with ground penetrating radar. In:

666 Hanninen, P, Autio S, editors. Proc Fourth Int Conf on GPR, 1992 Jun 8-13;

667 Rovaniemi, Geological Surv Finland Spec Paper 16;359-65.

668

669 23. Calkin SF, Allen RP, Harriman MP. Buried in the basement - geophysics role in a 670 forensic investigation. Proc of symp Appl Geophys Eng environ problems; 1995, 671 Denver: Env Eng Geophys Soc;397-403.

672

673 24. Nobes DC. The search for "Yvonne"': a case example of the delineation of a 674 grave using near-surface geophysical methods. J For Sci 2000;45:715-21.

675

676 25. Scott J, Hunter JR. Environmental influences on resistivity mapping for the 677 location of clandestine graves. In: Pye K, Croft DJ, editors. Forensic Geoscience:

678 Principles, Techniques and Applications. London: Geol Soc London Spec Pub $679 \quad 2004 ; 232: 33-8$.

680

681 26. Cheetham P. Forensic geophysical survey. In: Hunter J, Cox M, editors. Forensic 682 Archaeology: Advances in Theory and Practice, Abingdon: Routledge, 2005;62-95. 683 684 27. Ruffell A. Searching for the IRA “disappeared”: Ground Penetrating radar 685 investigation of a churchyard burial site. J For Sci 2005;50:1430-5.

686

687 28. Schultz JJ. Using ground-penetrating radar to locate clandestine graves of 688 homicide victims: forming forensic archaeology partnerships with law enforcement. 689 Homicide Studies 2007;11:15-29. 
690

691 29. Pringle JK, Jervis JR. Electrical resistivity survey to search for a recent

692 clandestine burial of a homicide victim, UK. For Sci Int 2010;202(1-3):e1-7.

693

694 30. Novo A, Lorenzo H, Ria F, Solla M. 3D GPR in forensics: finding a clandestine 695 grave in a mountainous environment. For Sci Int 2011;204:134-8.

696

697 31. Schultz JJ. The application of GPR for forensic grave detection. In: Dirkmaat DC, 698 editors. A companion to forensic anthropology, Hoboken, NJ: Blackwell, 2012, p.85699100.

700

701 32. Ruffell A, Pringle JK, Forbes S. Search protocols for hidden forensic objects 702 beneath floors and within walls. For Sci Int 2014;237:137-45.

703

704 33. France DL, Griffin TJ. Swanburg JG, Lindemann JW, Davenport GC, Trammell

705 V. et al. A multidisciplinary approach to the detection of clandestine graves. J For Sci $706 \quad 1992 ; 37: 1445-58$.

707

708 34. Strongman KB. Forensic applications of ground penetrating radar. In: Pilon J, 709 editor. Ground Penetrating Radar, Ottawa: Geological Survey of Canada Paper 90-4, 710 1992;203-11.

711

712 35. Freeland RS, Miller ML, Yoder RE, Koppenjan SK. Forensic applications of

713 FMCW and pulse radar. J Env Eng Geophys 2003;8:97-103. 714 
715 36. Pringle JK, Holland C, Szkornik K, Harrison M. Establishing forensic search

716 methodologies and geophysical surveying for the detection of clandestine graves in

717 coastal beach environments. For Sci Int 2012;219:e29-e36.

718

719 37. Pringle JK, Wisniewski K, Giubertoni M, Cassidy NJ, Hansen JD, Linford NJ, 720 Daniels RM. The use of magnetic susceptibility as a forensic search tool. For Sci Int $721 \quad 2015 a ; 246: 31-42$.

722

723

38. Schultz JJ, Collins ME, Falsetti AB. Sequential monitoring of burials containing 724 large pig cadavers using ground-penetrating radar. J For Sci 2006;51:607-16.

725

726

39. Schultz JJ. Sequential monitoring of burials containing small pig cadavers using 727 ground-penetrating radar. J For Sci 2008;53:279-87.

728

729

40. Pringle JK, Jervis J, Cassella JP, Cassidy NJ. Time-lapse geophysical

730 investigations over a simulated urban clandestine grave. J For Sci 2008;53:1405-17.

731

732

41. Schultz JJ, Martin MM. Controlled GPR grave research: Comparison of reflection profiles between 500 and $250 \mathrm{MHz}$ antennae. For Sci Int 2011;209:64-9.

734

42. Schultz JJ, Martin MM. Monitoring controlled graves representing common burial

736 scenarios with ground penetrating radar. J App Geophys 2012;83:74-89.

737

738 43. Schotmans EMJ, Fletcher JN, Denton J, Janaway RC, Wilson AS. Long-term

739 effects of hydrated lime and quicklime on the decay of human remains using pig 
740 cadavers as human body analogues: Field experiments. For Sci Int 2014a;238:141.e1-

741 e13.

742

743 44. Molina CM, Pringle JK, Saumett M, Hernandez O. Preliminary results of

744 sequential monitoring of simulated clandestine graves in Colombia, South America,

745 using ground penetrating radar and botany.For Sci Int 2015;248:61-70.

746

747 45. Pringle JK, Cassella JP, Jervis JR, Williams A, Cross P, Cassidy NJ. Soilwater

748 conductivity analysis to date and locate clandestine graves of homicide victims. J For

749 Sci in press.

750

751 46. Jervis JR, Pringle JK. A study of the affect of seasonal climatic factors on the

752 electrical resistivity response of three experimental graves. J App Geophys

$753 \quad 2014 ; 108: 53-60$.

754

755 47. Pringle JK, Jervis JR, Hansen JD, Cassidy NJ, Jones GM, Cassella JP.

756 Geophysical monitoring of simulated clandestine graves using electrical and Ground

757 Penetrating Radar methods: 0-3 years. J For Sci 2012b;57:1467-86.

758

759 48. Manhein MH. Decomposition rates of deliberate burials: a case study of

760 preservation. In: Haglund WD, Sorg MH, editors. Forensic taphonomy: the post-

761 mortem fate of human remains, Boca Raton, FL: CRC, 1996;469-81.

762

763 49. Peel MC, Finlayson BL, McMahon TA. Updated world map of the Köppen-

764 Geiger climate classification. Hydro Earth Sys Sci 2007;11:1633-44. 
766 50. Vass AA, Bass WM, Wolt JD, Foss JE, Ammons JT. Time since death

767 determinations of human cadavers using soil solution. J For Sci 1992;37:1236-53.

768

769 51. Carter DO, Tibbett M. Cadaver decomposition and soil: processes. In: Tibbett M, 770 Carter DO, editors. Soil Analysis in Forensic Taphonomy: Chemical and Biological 771 Effects of Buried Human Remains. Boca Raton: CRC Press, 2009;29-52.

772

773 52. Jervis JR, Pringle JK, Tuckwell GT. Time-lapse resistivity surveys over simulated 774 clandestine burials. For Sci Int 2009;192:7-13.

775

776 53. Rodriguez WC. Decomposition of buried and submerged bodies. In: Haglund

777 WD, Sorg MH, editors. Forensic Taphonomy: The Postmortem Fate of Human

778 Remains. Boca Raton: CRC Press, 1997;459-68.

779

780 54. Hansen JD, Pringle JK, Goodwin J. GPR and bulk ground resistivity surveys in 781 graveyards: locating unmarked burials in contrasting soil types. For Sci Int $782 \quad 2014 ; 237:$ e14-e29.

783

784 55. Bevan BW. The search for graves. Geophysics 1991;56:1310-9. 785

786 56. Clark AJ. Seeing beneath the soil: prospecting methods in archaeology, 2nd rev. 787 ed. New York: Routledge, 1996.

788 
789 57. Jervis JR. The detection of clandestine graves using electrical resistivity surveys:

790 results from controlled experiments and a case study (PhD dissertation). Keele: Keele

791 University, 2011.

792

793 58. Ellwood BB, Owsley DW, Ellwood SH, Mercado-Allinger PA. Search for the

794 grave of the hanged Texas gunfighter, William Preston Longley. Hist Arch

795 1994;28:94-112.

796

797 59. Ruffell A, McCabe A, Donnelly C, Sloan B. Location and assessment of an

798 historic (150-160 years old) mass grave using geographic and ground penetrating

799 radar investigation, NW Ireland. J For Sci 2009;54:382-94.

800

801 60. Powell K. Detecting human remains using near-surface geophysical instruments.

802 Expl Geophys 2004;35:88-92.

803

804 61. Blom G, Davidson A, Pringle J, Williams A, Lamont A, Cassella JP. Chemical

805 markers for the detection of clandestine graves - development of a complimentary

806 technique for forensic geophysics? Recent Work in Arch Geophys and For Geosci:

807 Future Horizons Conf, Geol Soc London, 2-3 December, 2014.

808

809 
810

811

812 FIG. 1. (A) Map of survey area (dashed rectangle) with graves, L1/2 GPR and ERI

813 2D profile lines, lysimeter positions and UK location map all shown (inset). (B)

814 Study site, (C) naked pig grave, (D) wrapped pig grave, (E) pig lysimeter grave and

815 (F) soil fluid measurement photographs respectively. Modified from [47].

817 FIG. 2. Summary of monthly study site statistics of total rainfall (bars) and average

818 temperature (line) data at $0.3 \mathrm{~m} \mathrm{bgl}$ (below ground level), measured over the four to

819 six year study period. Dashed average temperature line is for zero to three years

820 survey period [47] shown for comparison.

821

824

825

826

828

831

832

833

834

FIG. 4. Fixed-offset processed electrical resistivity datasets for the four to six year study period (year and season shown). Red, green and blue rectangles indicate positions of naked pig, empty and wrapped pig graves respectively (see Fig. 1A).

FIG. 5. Individually inverted 2D Electrical Resistivity Imaging (ERI) Wenner array 
835 shown); model inversion errors (RMS) for the fifth iterations are indicated. Positions

836 of naked pig, empty and wrapped pig graves are also shown (dashed lines). See Fig.

837 1A (ERI/ERI') for location.

838

839 FIG. 6(A). Key sequential processed 110, 225, 450 and $900 \mathrm{MHz}$ dominant

840 frequency GPR profiles for 39 - 54 post-burial months (year and season shown) that

841 bisect the naked and wrapped pig graves respectively (Fig. 1A for location).

842

843 FIG. 6(B). Key sequential processed 110, 225, 450 and $900 \mathrm{MHz}$ dominant

844 frequency GPR profiles for 57 - 72 post-burial months (year and season shown) that

845 bisect the naked and wrapped pig graves respectively (Fig. 1A for location).

846

847 FIG. 7. Summary qualitative analysis plot of resistivity data over the complete six

848 year survey period with this paper 4-6 year survey period to the right of the vertical

849 dashed lines (see key and text). Modified from [47].

850

851 FIG. 8. Summary quantitative analysis plots of fixed-offset resistivity data collected

852 over the complete six year survey period with this paper 4-6 year survey period to the

853 right of the vertical dashed line. (A) Standard deviations (SD) for each survey, note

854 SD values are highest in late summer; residual volume analysis of (B) naked pig

855 cadaver and (C) wrapped pig cadaver (see text). Modified from [46].

856

857 
1

2

3

4

5

6

7

8

9

10

11

12

13

14

15

16

17

18

19

20

21

22

23

24

25

26

27

28

29

30

31

32

33

34

35

36

37

38

39

40

41

42

43

44

45

46

47

48

49

50

51

52

53

54

55

56

57

58

59

60

858 TABLE CAPTION:

859

860 TABLE 1. Summary of geophysical surveys and their respective geophysical

861 anomalies in this study (4-6 year results below horizontal line). ${ }^{+}$Burial date was $7^{\text {th }}$

862 December 2007. *ADD date based on average daily site temperatures at $0.3 \mathrm{~m} \mathrm{bgl}$

863 (see [47]).

864

865 
866

867 Additional Information and Reprint Requests:

868 Jamie K. Pringle, Ph.D.

869 School of Physical Sciences \& Geography,

870 William Smith Building,

871 Keele University,

872 Keele,

873 Staffordshire,

874 ST5 5BG,

875 U.K.

876 E-mail: j.k.pringle@keele.ac.uk

877 

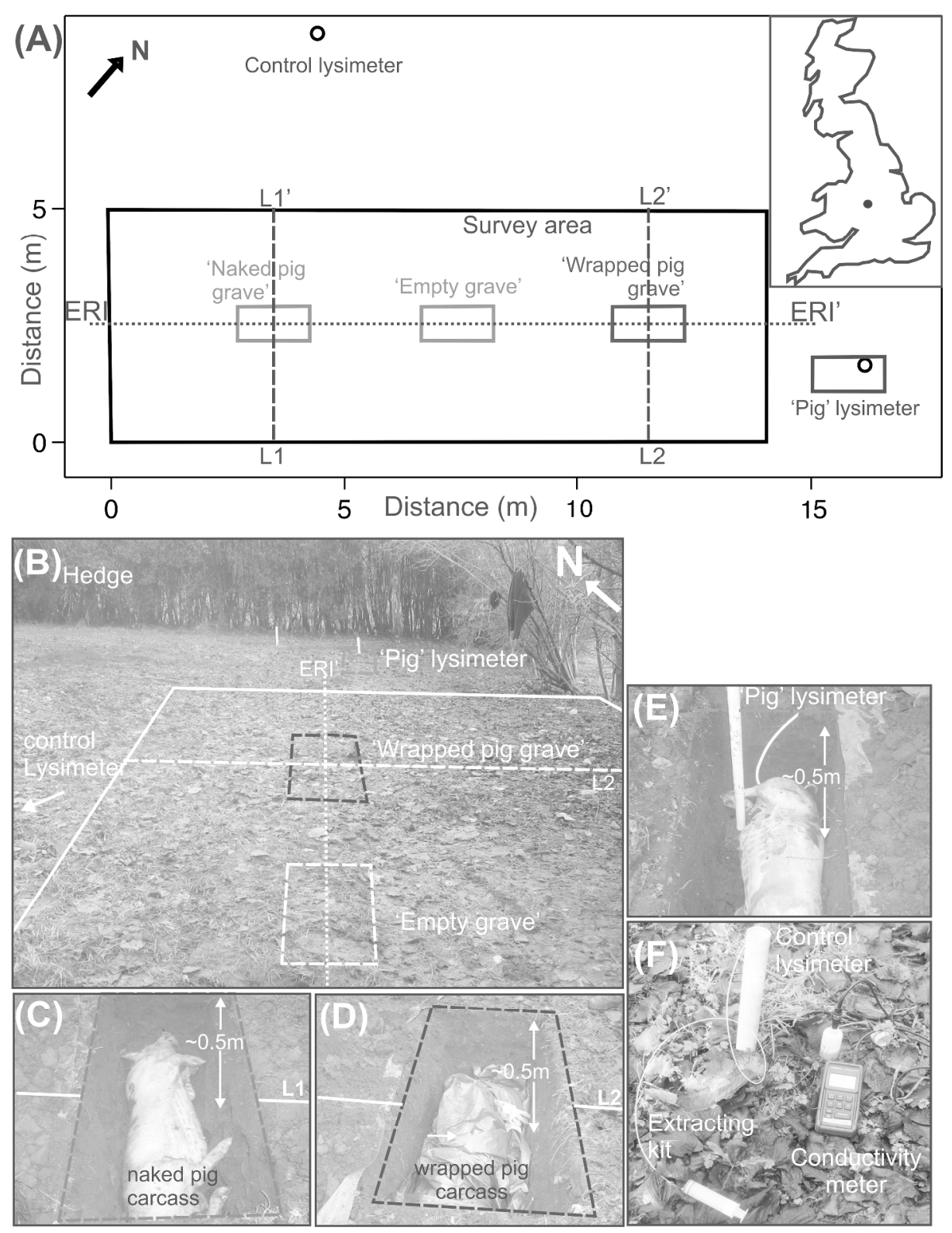

FIG. 1. (A) Map of survey area (dashed rectangle) with graves, L1/2 GPR and ERI 2D profile lines, lysimeter positions and UK location map all shown (inset). (B) Study site, (C) naked pig grave, (D) wrapped pig grave, (E) pig lysimeter grave and (F) soil fluid measurement photographs respectively. Modified from [47]. 

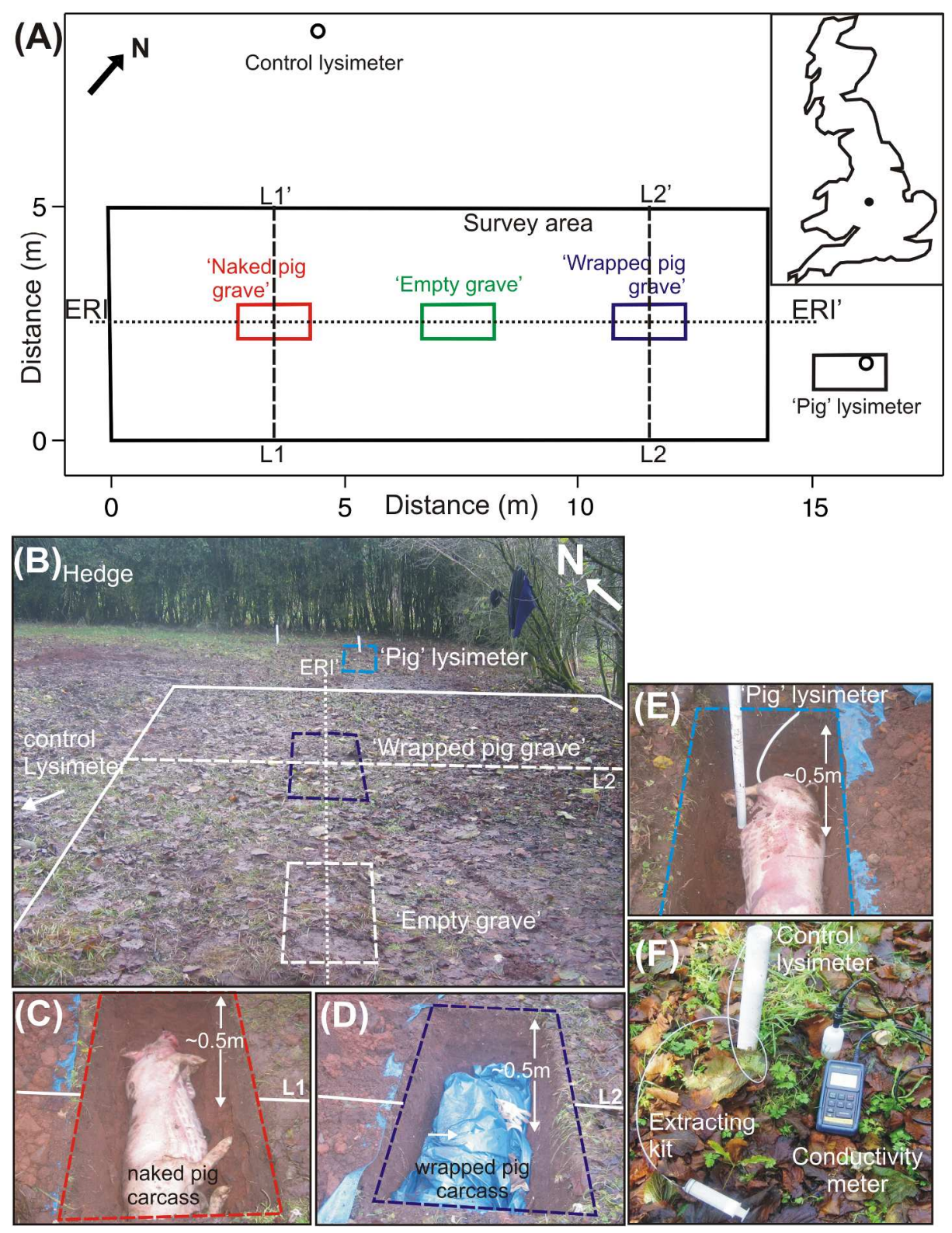

FIG. 1. (A) Map of survey area (dashed rectangle) with graves, L1/2 GPR and ERI 2D profile lines, lysimeter positions and UK location map all shown (inset). (B) Study site, (C) naked pig grave, (D) wrapped pig grave, (E) pig lysimeter grave and (F) soil fluid measurement photographs respectively. Modified from [47]. 
39

40

41

42

43

44

45

46

47

48

49

50

51

52

53

54

55

56

57

58

59

60

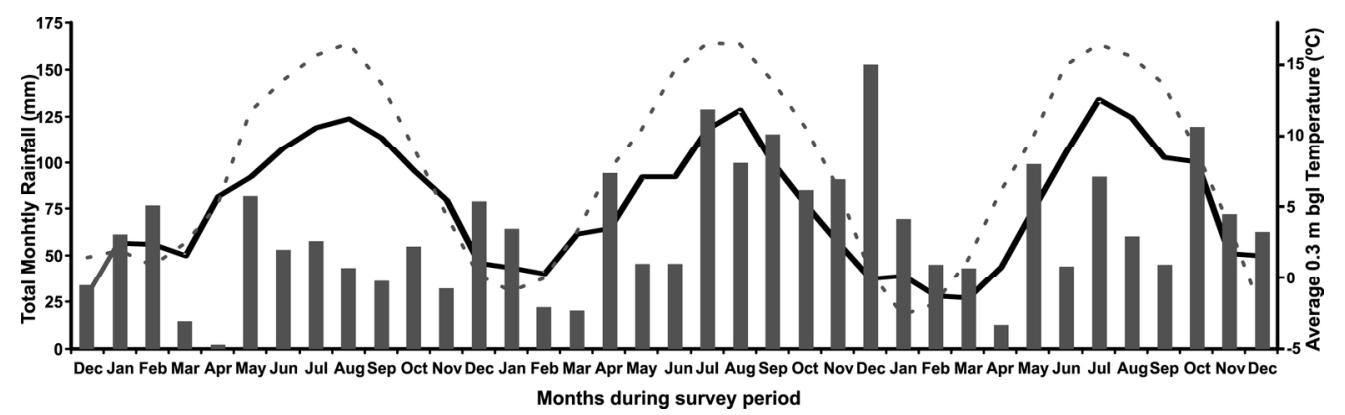

FIG. 2. Summary of monthly study site statistics of total rainfall (bars) and average temperature (line) data at $0.3 \mathrm{~m} \mathrm{bgl}$ (below ground level), measured over the four to six year study period. Dashed average temperature line is for zero to three years survey period (40) shown for comparison. $86 \times 25 \mathrm{~mm}(600 \times 600 \mathrm{DPI})$ 


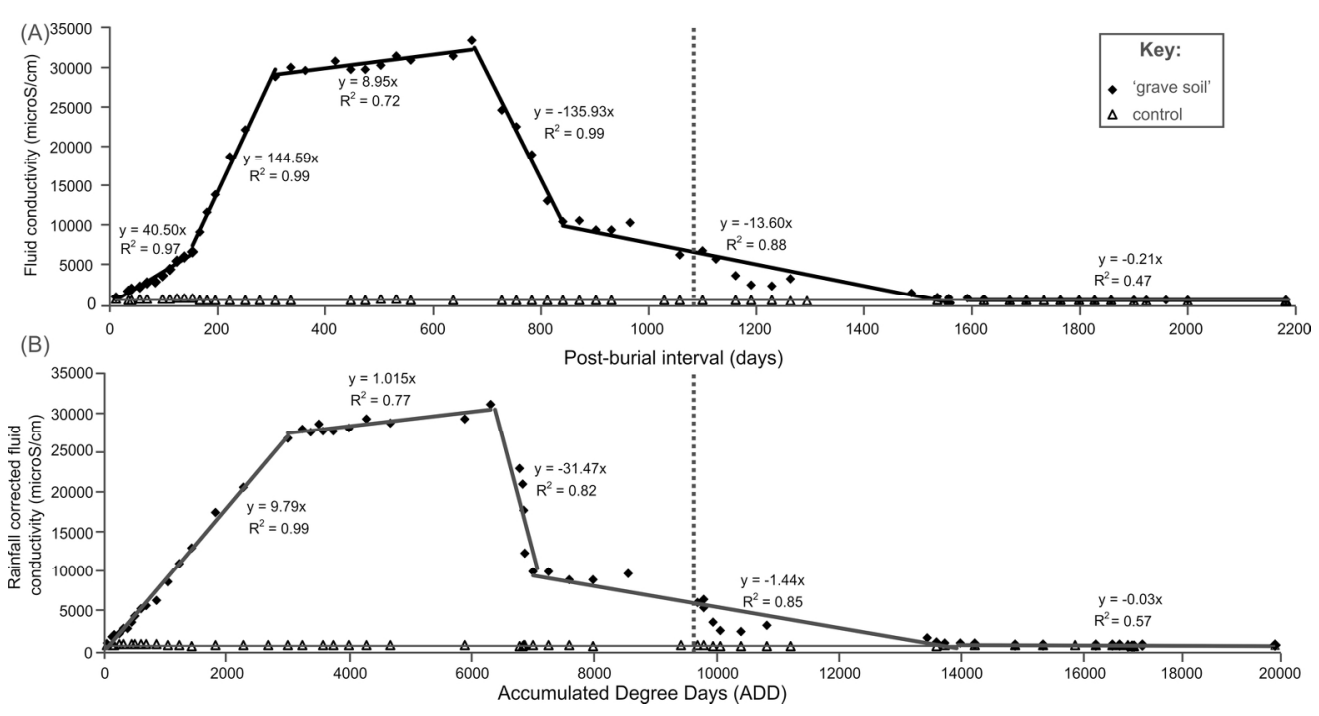

$173 \times 90 \mathrm{~mm}(300 \times 300$ DPI $)$ 

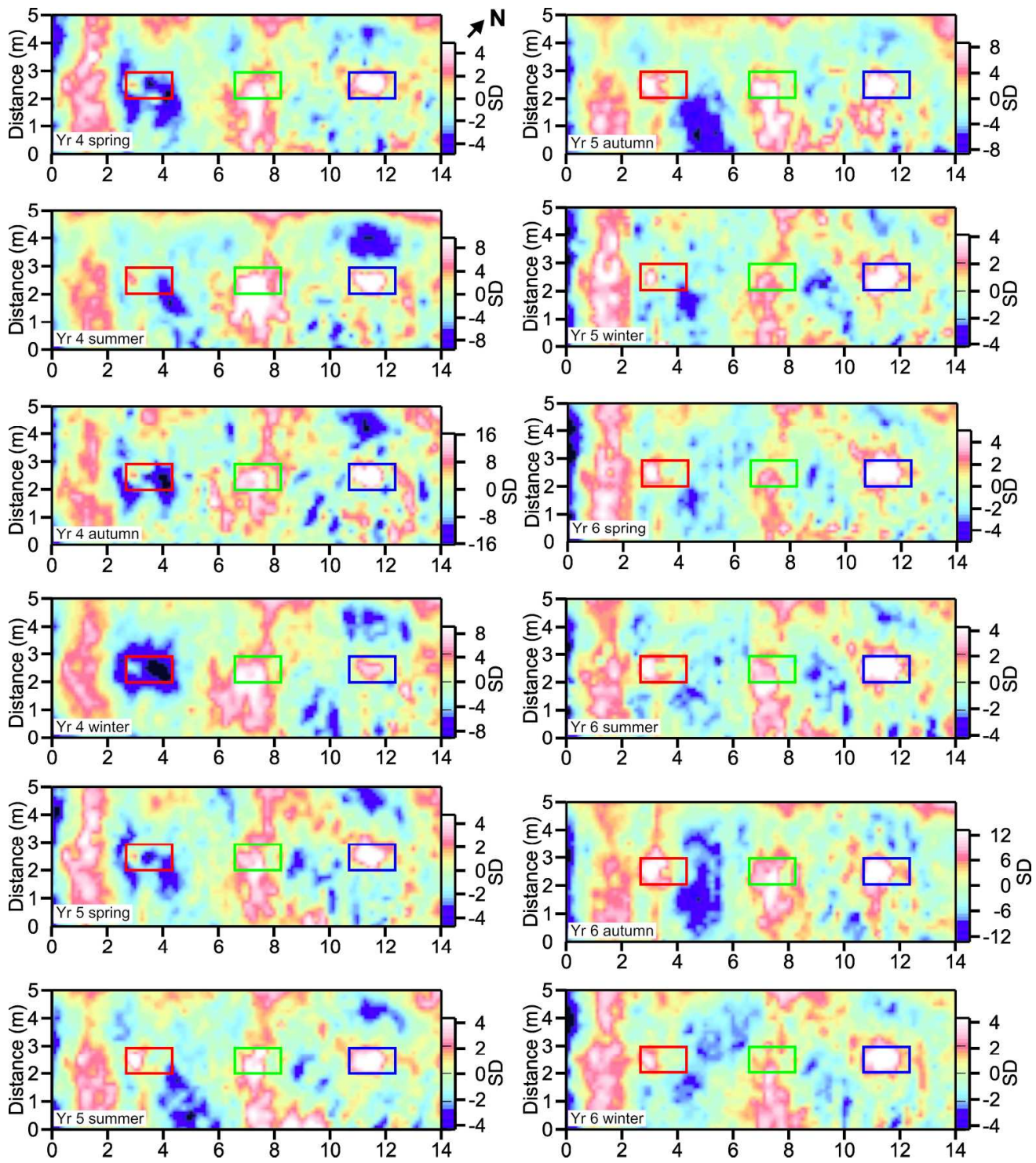

FIG. 4. Fixed-offset processed electrical resistivity datasets for the four to six year study period (year and season shown). Red, green and blue rectangles indicate positions of naked pig, empty and wrapped pig graves respectively (see Fig. $1 \mathrm{~A}$ ). $209 \times 235 \mathrm{~mm}(300 \times 300 \mathrm{DPI})$ 

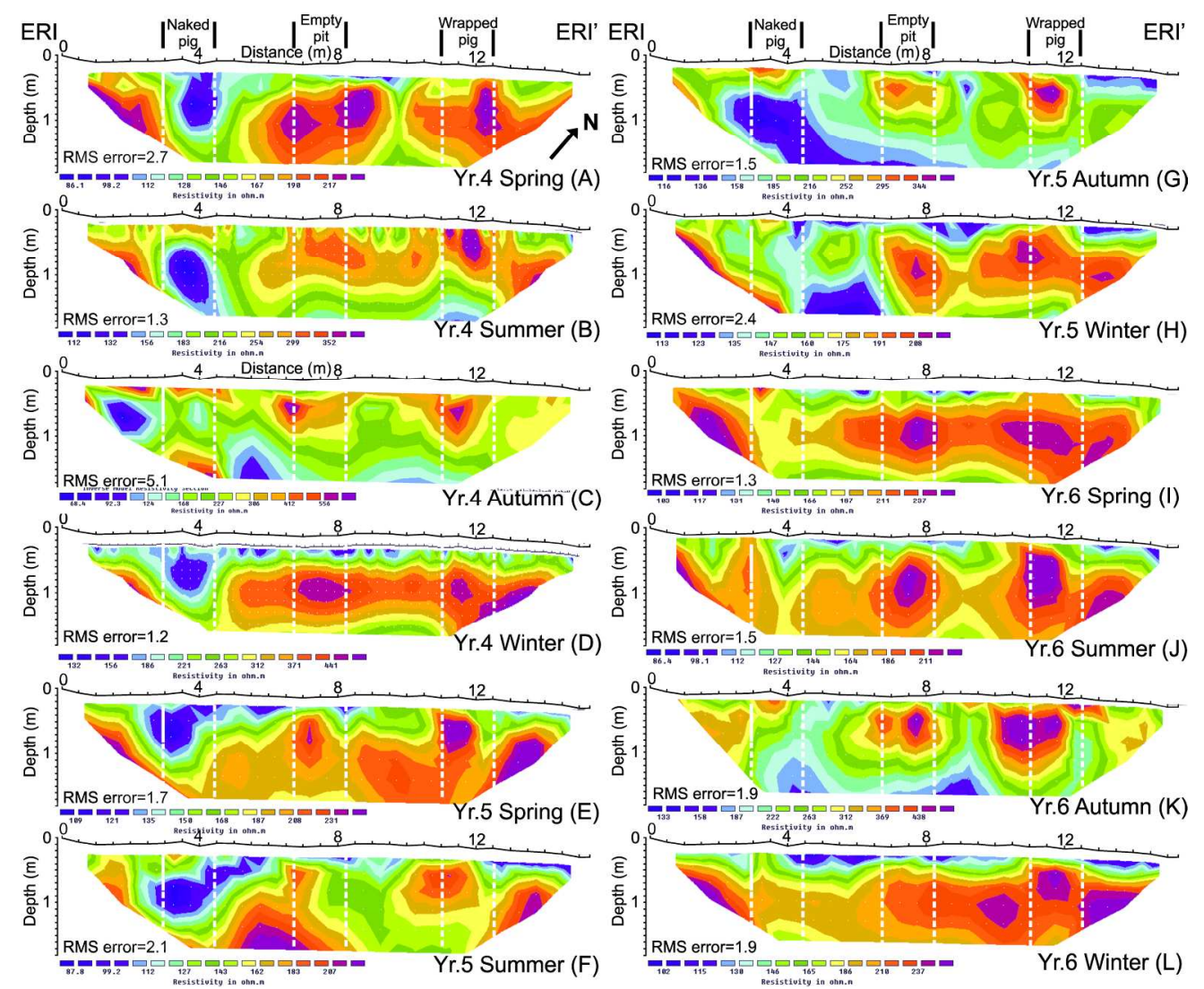

FIG. 5. Individually inverted 2D Electrical Resistivity Imaging (ERI) Wenner array ( $0.5 \mathrm{~m}$ spaced electrode) profiles for the four to six year study period (year and season shown); model inversion errors (RMS) for the fifth iterations are indicated. Positions of naked pig, empty and wrapped pig graves are also shown (dashed lines). See Fig. $1 \mathrm{~A}$ (ERI/ERI') for location. $214 \times 179 \mathrm{~mm}(300 \times 300 \mathrm{DPI})$ 


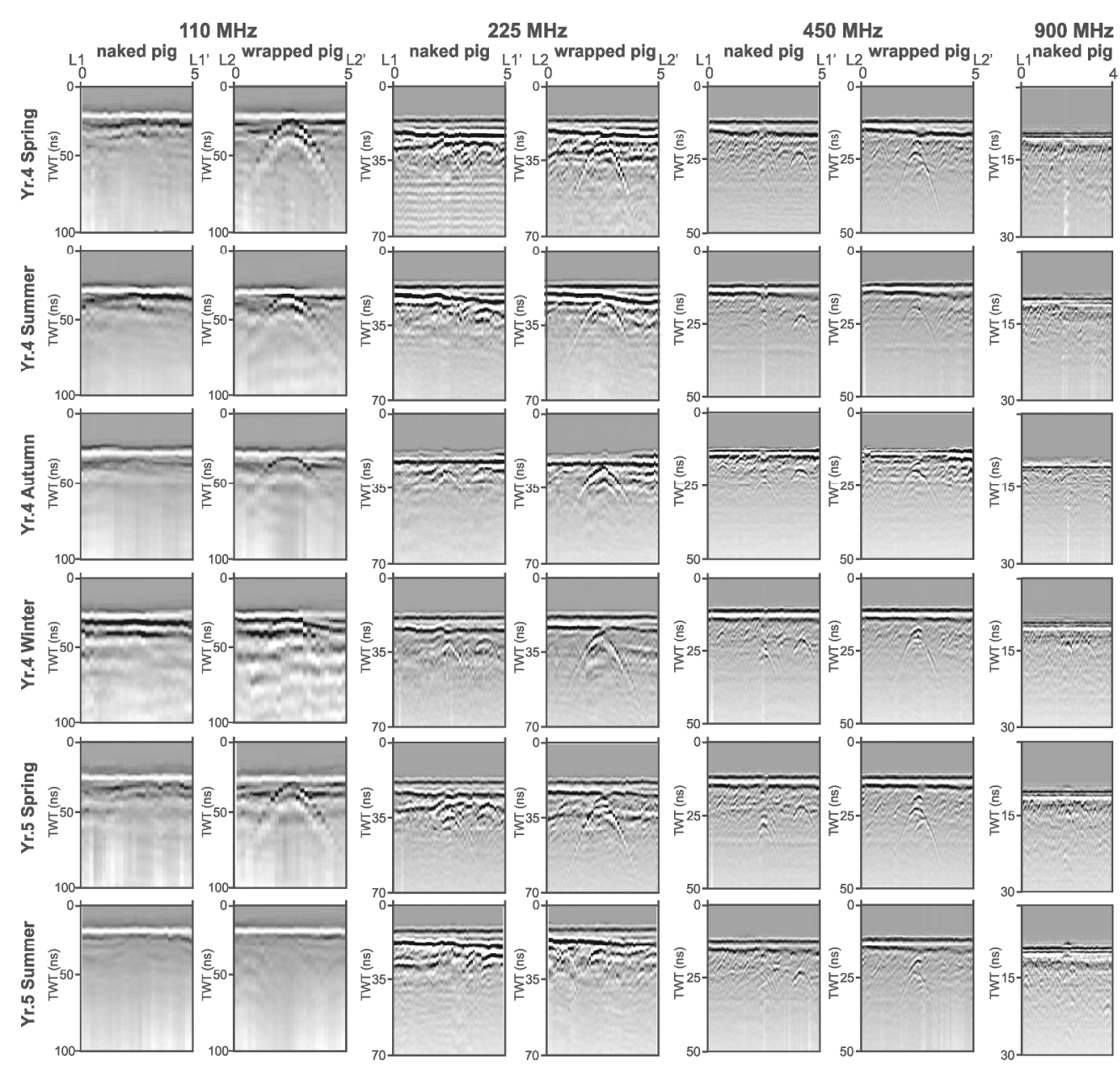

FIG. 6(A). Key sequential processed 110, 225, 450 and $900 \mathrm{MHz}$ dominant frequency GPR profiles for 39 54 post-burial months (year and season shown) that bisect the naked and wrapped pig graves respectively (Fig. 1A for location). $313 \times 295 \mathrm{~mm}(300 \times 300$ DPI $)$ 


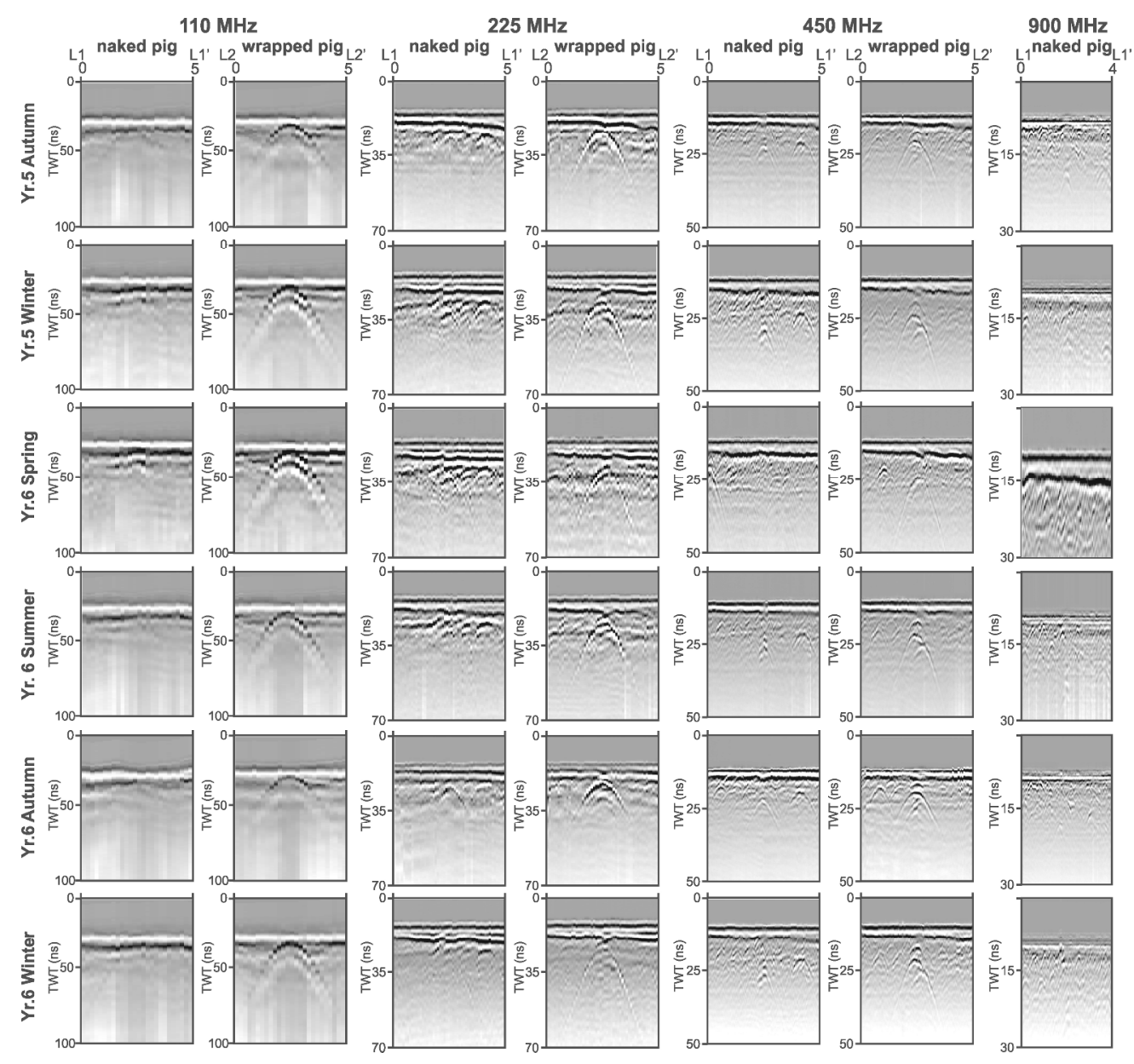

FIG. 6(B). Key sequential processed 110, 225, 450 and $900 \mathrm{MHz}$ dominant frequency GPR profiles for 57 72 post-burial months (year and season shown) that bisect the naked and wrapped pig graves respectively (Fig. 1A for location). $317 \times 295 \mathrm{~mm}(300 \times 300 \mathrm{DPI})$ 
FIG. 7. Summary qualitative analysis plot of resistivity data over the complete six year survey period with this paper 4-6 year survey period to the right of the vertical dashed lines (see key and text). Modified from $(40)$.

$76 \times 18 \mathrm{~mm}(600 \times 600 \mathrm{DPI})$ 
FIG. 7. Summary qualitative analysis plot of resistivity data over the complete six year survey period with this paper 4-6 year survey period to the right of the vertical dashed lines (see key and text). Modified from $(40)$.

$76 \times 18 \mathrm{~mm}(600 \times 600 \mathrm{DPI})$ 
(A)

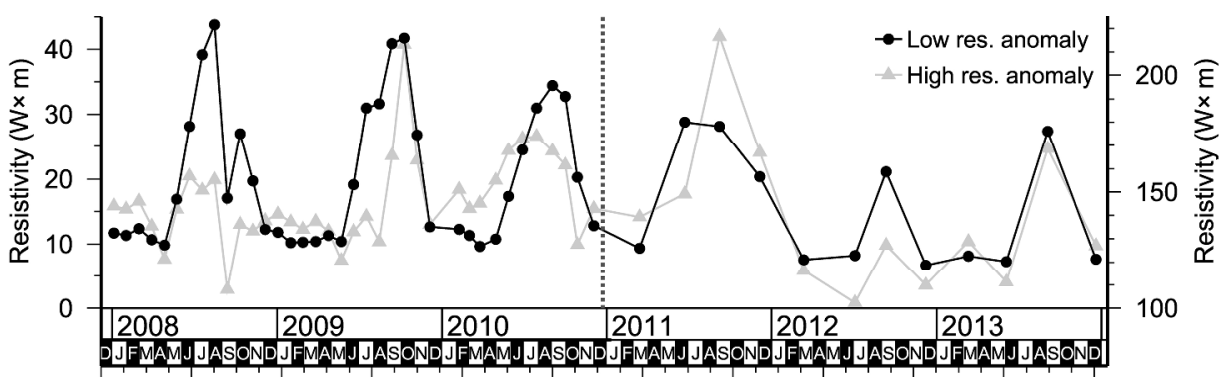

(B)

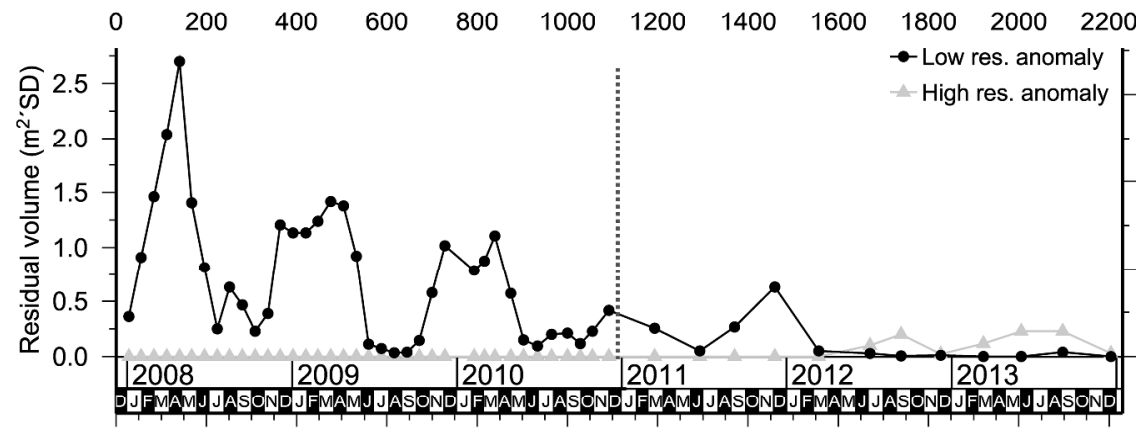

$\begin{array}{llllllllllll}0 & 200 & 400 & 600 & 800 & 1000 & 1200 & 1400 & 1600 & 1800 & 2000 & 2200\end{array}$

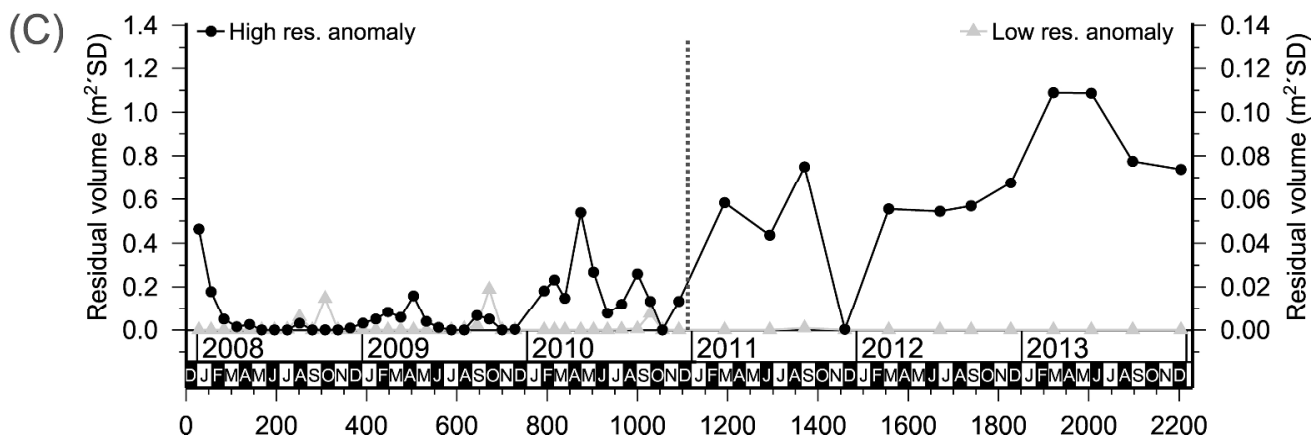

FIG. 8. Summary quantitative analysis plots of fixed-offset resistivity data collected over the complete six year survey period with this paper 4-6 year survey period to the right of the vertical dashed line. (A) Standard deviations (SD) for each survey, note SD values are highest in late summer; residual volume analysis of (B) naked pig cadaver and (C) wrapped pig cadaver (see text). Modified from (39). $176 \times 171 \mathrm{~mm}(600 \times 600 \mathrm{DPI})$ 


\begin{tabular}{|c|c|c|c|c|c|c|c|c|c|c|c|c|c|}
\hline \multirow[t]{2}{*}{$\begin{array}{l}\text { Survey } \\
\text { date(s) }\end{array}$} & \multirow{2}{*}{$\begin{array}{l}\text { Survey } \\
\text { day after } \\
\text { burial }^{+}\end{array}$} & \multirow{2}{*}{$\begin{array}{l}\text { Accum- } \\
\text { ulated } \\
\text { Degree } \\
\text { Day } \\
\text { (ADD)* }\end{array}$} & \multicolumn{2}{|c|}{$\begin{array}{c}\text { Twin electrode }(0.5 \mathrm{~m}) \\
\text { array (Fig.4) }\end{array}$} & \multicolumn{2}{|c|}{ ERI profile (Fig. 5) } & \multicolumn{2}{|c|}{110 MHz (Fig.6) } & \multicolumn{2}{|c|}{225 MHz (Fig.6) } & \multicolumn{2}{|c|}{450 MHz (Fig.6) } & \multirow{2}{*}{\begin{tabular}{l}
\multicolumn{1}{c}{900} \\
MHz \\
Naked \\
pig
\end{tabular}} \\
\hline & & & Naked pig & $\begin{array}{l}\text { Wrapped } \\
\text { pig }\end{array}$ & $\begin{array}{l}\text { Naked } \\
\text { pig }\end{array}$ & $\begin{array}{l}\text { Wrapped } \\
\text { pig }\end{array}$ & $\begin{array}{l}\text { Naked } \\
\text { pig }\end{array}$ & $\begin{array}{l}\text { Wrapped } \\
\text { pig }\end{array}$ & $\begin{array}{l}\text { Naked } \\
\text { pig }\end{array}$ & $\begin{array}{c}\text { Wrapped } \\
\text { pig }\end{array}$ & $\begin{array}{l}\text { Naked } \\
\text { pig }\end{array}$ & $\begin{array}{l}\text { Wrapped } \\
\text { pig }\end{array}$ & \\
\hline 07.03 .2008 & 91 & 454 & None & Excellent & Poor & Good & Good & Excellent & Good & Excellent & Poor & Excellent & Poor \\
\hline 05.06 .2008 & 181 & 1,314 & Excellent & Poor & Poor & None & Good & Excellent & Poor & Excellent & Poor & Excellent & None \\
\hline 01.09 .2008 & 269 & 2,727 & Excellent & Poor & Good & None & Poor & Excellent & Poor & Excellent & Poor & Excellent & Good \\
\hline 04.12 .2008 & 363 & 3,732 & Excellent & None & Excellent & None & Good & Excellent & Good & Excellent & Good & Excellent & Good \\
\hline 06.03 .2009 & 455 & 4,080 & Excellent & Poor & Good & Poor & Poor & Excellent & Poor & Excellent & Poor & Excellent & None \\
\hline 20.05.2009 & 530 & 4,765 & Excellent & Poor & Excellent & Poor & Poor & Excellent & Poor & Excellent & Poor & Excellent & None \\
\hline 11.08 .2009 & 613 & 6,083 & Excellent & Poor & Excellent & Poor & Poor & Excellent & Poor & Excellent & Poor & Good & None \\
\hline 13.11 .2009 & 707 & 7,371 & Poor & Poor & Poor & None & Poor & Excellent & None & Excellent & None & Good & None \\
\hline 20.04.2010 & 865 & 8,084 & Excellent & Good & Excellent & Poor & Poor & Excellent & None & Excellent & No & Go & None \\
\hline 28.06 .2010 & 934 & 8,976 & Poor & Poor & Excellent & Poo & Poor & Good & None & Good & No & Po & None \\
\hline 28.09 .2010 & 1,026 & 11,026 & Poor & Good & Poor & Good & Poor & Excellent & None & Excellent & None & Good & None \\
\hline 03.12 .2010 & 1,092 & 11,026 & Good & Good & Excellent & Good & None & Excellent & None & Excellent & None & Poor & None \\
\hline 15.03 .2011 & 1,194 & 11,401 & Good & $\overline{\text { Good }}$ & Excellent & Good & Poor & Excellent & None & Excellent & Poor & Excellent & None \\
\hline 22.06 .2011 & 1,293 & 12,554 & None & Good & Excellent & Good & Poor & Excellent & None & Excellent & None & Good & None \\
\hline 09.09.2011 & 1,370 & 13,791 & Good & Poor & None & Poor & Poor & Good & Poor & Excellent & Poor & Good & None \\
\hline 06.12 .2011 & 1,460 & 14,827 & Excellent & Poor & Good & Poor & None & Good & Poor & Excellent & Poor & Excellent & Poor \\
\hline 12.03 .2012 & 1,557 & 15,294 & Good & Good & Good & Good & Poor & Excellent & Poor & Excellent & Poor & Good & Poor \\
\hline 03.07 .2012 & 1,670 & 16,577 & None & Good & Good & Good & None & Poor & None & Poor & None & Good & None \\
\hline 10.09 .2012 & 1,739 & 17,750 & Poor & Poor & Poor & Good & Poor & Good & None & Good & None & Good & Poor \\
\hline 07.12 .2012 & 1,827 & 18,636 & None & Good & None & Poor & Poor & Excellent & None & Excellent & None & Good & None \\
\hline 12.03 .2013 & 1,922 & 19,030 & Poor & Excellent & None & Good & Poor & Excellent & None & Good & Poor & Good & None \\
\hline 04.06 .2013 & 2,006 & 19,668 & Poor & Excellent & None & Excellent & None & Good & None & Good & Poor & Good & None \\
\hline 04.09 .2013 & 2,098 & 21,212 & Good & Excellent & None & Excellent & None & Good & Poor & Good & Poor & Good & None \\
\hline 18.12 .2013 & 2,204 & 22,345 & Poor & Excellent & None & Good & Poor & Good & None & Good & None & Good & None \\
\hline
\end{tabular}

TABLE 1. Summary of geophysical surveys and their respective geophysical anomalies in this study (4-6 year results below

horizontal line). ${ }^{+}$Burial date was $7^{\text {th }}$ December 2007. ${ }^{*}$ ADD date based on average daily site temperatures at $0.3 \mathrm{~m}$ bgl (see [47]). 
Long-term Ggeophysical monitoring of simulated clandestine graves using electrical and Ground Penetrating Radar methods: 4-6 years after burial

\section{3}

4 Jamie K. Pringle, ${ }^{1}$ Ph.D.; John R. Jervis, ${ }^{1,2}$ Ph.D.; Daniel Roberts, ${ }^{1}$ M.Sc.; Henry C.

5 Dick, ${ }^{1}$ B.Sc; Kris Wisniewski, ${ }^{1}$ B.Sc; Nigel J. Cassidy, ${ }^{1}$ Ph.D.; and John P. Cassella, ${ }^{3}$

$6 \quad$ Ph.D.

7

$8{ }^{1}$ School of Physical Sciences \& Geography, Keele University, Keele, Staffordshire

9 ST5 5BG, U.K.

$10 \quad{ }^{2}$ Exploration Electronics Ltd., London Road, Beccles, Suffolk, NR34 8TS, U.K.

$11{ }^{3}$ Department of Forensic and Crime Science, Staffordshire University, College Road,

12 Stoke-on-Trent, Staffordshire ST4 2DE, U.K.

13

14 Sources of funding:

15

16 A U.K. HEFCE SRIF2 equipment grant funded purchase of geophysical equipment. 17

18 


\section{ABSTRACT}

21 This ongoing monitoring study provides forensic search teams with systematic

22 geophysical data over simulated clandestine graves for comparison to active cases.

23 Simulated 'wrapped', 'naked' and 'control' burials were created. Multiple

24 geophysical surveys were collected over six-years, here showing data from four to six

25 years after burial. Electrical resistivity (fixed-offsettwin electrode and ERI), multi-

26 frequency GPR, grave and background soilwater were collected. Resistivity surveys

27 revealed the naked burial had low-resistivity anomalies up to year four but then

28 difficult to image, whereas the wrapped burial had consistent large high-resistivity

29 anomalies. GPR 110-900 MHz frequency surveys showed the wrapped burial could

30 be detected throughout, but the naked burial was either not detectable or poorly not

31 resolved. $225 \mathrm{MHz}$ frequency GPR data were optimal. Soil water analyses showed

32 decreasing (year four-five) to background (year six) conductivity values. Results

33 suggest both resistivity and GPR surveying if burial style unknown, with winter to

34 spring surveys optimal and increasingly important as time increases.

36 Keywords: forensic science; forensic geophysics; clandestine grave; monitoring;

37 electrical resistivity; Gground Ppenetrating Rradar; conductivity 
40 Forensic search methods vary widely, for example, in the UK a search strategist is

41 usually involved in a case at an early stage to decide upon the highest probability of

42 search success [1], whereas in other countries a search may not be methodical,

43 investigations may not be standardised and a variety of techniques are undertaken,

44 depending upon local experience [2]. Metal detector search teams [3-5] and specially

45

46

47

48

49

50

51

52

53

54

55

56

57

58

59

60

61 Near-surface geophysical methods rely on there being a detectable physical contrast

62

63

64 trained search dogs [5- 7 ] are both commonly used during either initial investigations or as part of a phased sequential programme.

Forensic investigators have been increasingly using geoscientific methods to aid in civil or criminal forensic investigations, predominantly to assist search teams or for

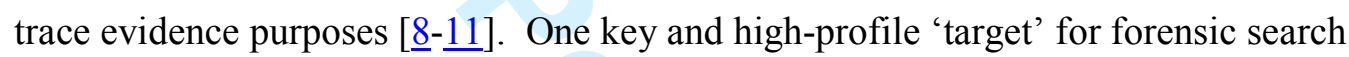
teams to detect and locate is human remains buried within clandestine graves $[1,5,12]$.

These searches generally start from large-scale remote sensing methods [1ㅇ-14 ], aerial and ultraviolet photography $[\underline{10}, \underline{15}]$, thermal imaging [16], to ground-based observations of vegetation changes [4]], surface geomorphology changes [17], soil type [1] and depositional environment(s) [1ㅜ], near-surface geophysics [11], diggability surveys [1] and probing of anomalous areas $[\underline{18}, \underline{19}]$ before topsoil removal [4] , and finally controlled excavation and recovery $[5, \underline{15}, \underline{20}]$. A typical search will only use a few of these techniques, depending on the circumstances of each case (Colin Hope, pers. comm.).

\section{0} between the target and the background (or host) materials (see [21]). Near-surface geophysical surveys have been used to try and locate clandestine graves in a number of reported criminal search investigations $[3, \underline{5}, \underline{22}-\underline{32}]$. Geophysical surveys collected 
65 over simulated burials have been undertaken in order to collect control data (e.g. [33-

37]. These studies have shown that the resulting geophysical responses could be well predicted, although responses seem to vary both temporally after burial and between different study sites. A few studies have also collected repeat (time-lapse) geophysical surveys over controlled experiments (e.g. [26, $\underline{38}-\underline{44]})$, which have documented temporal changes in geophysical responses over their study periods.

71 However, uncertainties still remain over what and how long temporal variations occur

72 in geophysical surveys after burial, with study survey sites needing to be fully

73 characterised (e.g. geologically and climatologically) to allow comparisons with other

74 studies or indeed for active forensic cases. Documenting temporal changes is

75 important as geophysical responses from recent clandestine burials are known to vary

more than for archaeological graves. Potential reasons for this could be the temporal changes in grave soil characteristics, decomposition products [45], climatic variations, soil moisture content [46] and other site specific factors (see [11]).

This study continued the systematic assessment of the changing geophysical response of simulated clandestine graves during four to six years after burial. Geophysical survey results from zero to three years after burial were published in [47]. A clandestine grave was defined in this study as an unrecorded burial that has been hand-excavated and dug $<1 \mathrm{~m}$ depth below ground level (bgl). It should be noted that geophysical results will vary depending upon the depth of burial and indeed on local soil type as [11] reviews. The discovered graves published in $[\underline{15}, \underline{48]}$ were usually rectangular in plan-view, mostly hurriedly hand dug using garden implements and usually just large enough to deposit the victim before being back-filled with excavated soil and associated surface debris. [48] also detailed that almost half of the 87 
90 documented U.S. cases were either clothed or encased in material (plastic or fabric),

91 so the authors decided to use two end member scenarios for this study; namely one burial containing a naked cadaver and another containing a cadaver wrapped in a tarpaulin. It is, however, emphasised that these obviously do not represent all types of potential style of burial with [42] considering other scenarios.

96 There are many potential near-surface geophysical search techniques that could be

97 utilised to search for clandestine graves that the [47] monitoring paper summarises; this ongoing study has concentrated on collecting electrical resistivity (fixed-offset and Electrical Resistivity Imaging 2D profiles) and Ground Penetrating Radar (110 -

$100 \quad 900 \mathrm{MHz}$ frequency 2D profiles. Resistivity surveys showed consistent low

101 anomalies, compared to background values, for a naked burial, in contrast with the

102 wrapped burial which had smaller and varied low/high anomalies and was thus harder

103 to locate [47]. Analyses of decompositional fluids showed highest conductivity

104 values, compared to background soilwater, was $\sim 1$ year to $\sim 2$ years after burial before

105 subsequently decreasing [47]. GPR surveys finally showed low frequency antennae

106 were consistently optimal for target detection [47].

108 The aims of this continued four to six year geophysical monitoring study of different

109 simulated burial style clandestine burials were to answer some basic questions posed

110 by forensic search teams. Appropriate site data (rainfall, temperature, soil and 'grave'

111 water conductivities) were also continued to be simultaneously collected in order to

112 allow comparisons with other research studies and criminal search investigations.

113 Basic forensic search questions which willwere continued to be addressed by this 114 study were: 


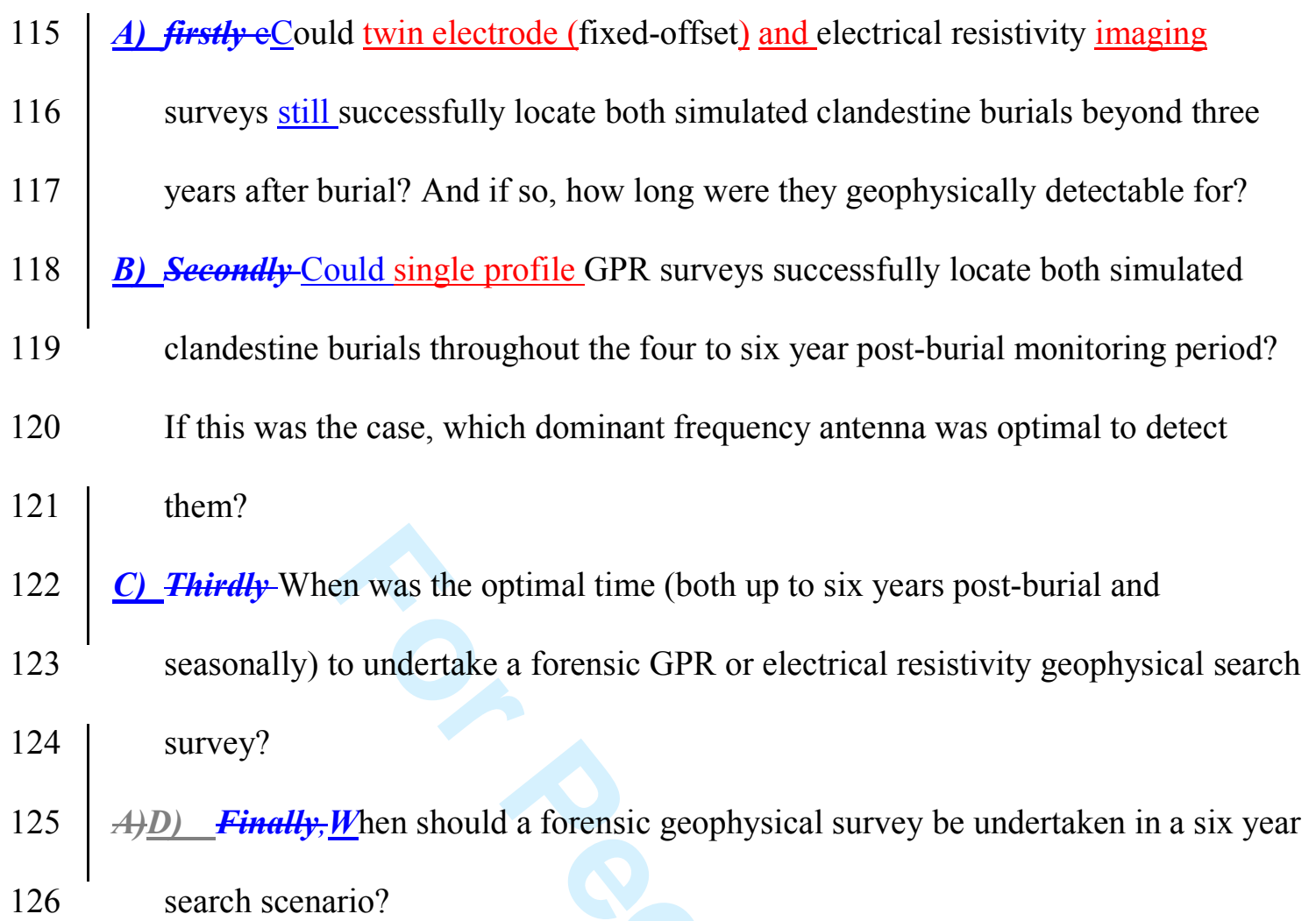
127 


\section{Methodology}

129

130 Study site

132 The chosen controlled test site was located on Keele University campus, $\sim 200 \mathrm{~m}$

133 above sea level, close to the town of Newcastle-under-Lyme in Staffordshire, UK.

134 The local climate is temperate, which is typical for the UK [49]. The study site was a

135 grassed, small rectangular area $(\sim 25 \mathrm{~m} \mathrm{x} \sim 25 \mathrm{~m})$, surrounded by small deciduous trees

136 (Fig. 1). The geophysical survey area measured $5 \mathrm{~m} \mathrm{x} 14 \mathrm{~m}$ and sloped by

137 approximately $3^{\circ}$ from northwest to southeast. Within this area were the 'naked pig'

138 grave, the empty grave and the 'wrapped pig' grave emplaced in sandy loam soil (Fig.

139 1). [47] provides other relevant background site information.

140

141 The test site was located $\sim 200 \mathrm{~m}$ from the Keele University weather observation

142 station, which continually measured daily rainfall and air and ground temperatures as

143 well as having soil temperature probes at $0.1 \mathrm{~m}, 0.3 \mathrm{~m}$ and $1.0 \mathrm{~m}$ below ground level.

144 Figure 2 shows a monthly summary of the total rainfall and average temperature data

145 over the monitoring period with temperature data for the zero to three year monitoring

146 study also shown for comparison. The local weather station data showed that total

147 monthly rainfall during the four to six year study period ranged from $2.6 \mathrm{~mm}$ to 152.2

$148 \mathrm{~mm}$, with an overall monthly average of $64.7 \mathrm{~mm}$, the same as for the zero to three

149 year monitoring period [47]. Average monthly air temperatures ranged from $-1.2{ }^{\circ} \mathrm{C}$

150 to $12.8^{\circ} \mathrm{C}$, with an overall monthly average of $5.5^{\circ} \mathrm{C}, 3.2^{\circ} \mathrm{C}$ colder than for the zero

151 to three year monitoring period (Fig. 2). However, note at $0.3 \mathrm{~m} \mathrm{bgl}$ the average

152 temperature was $10.2^{\circ} \mathrm{C}$ for the three four to six year monitoring period and $9.8^{\circ} \mathrm{C}$ for 


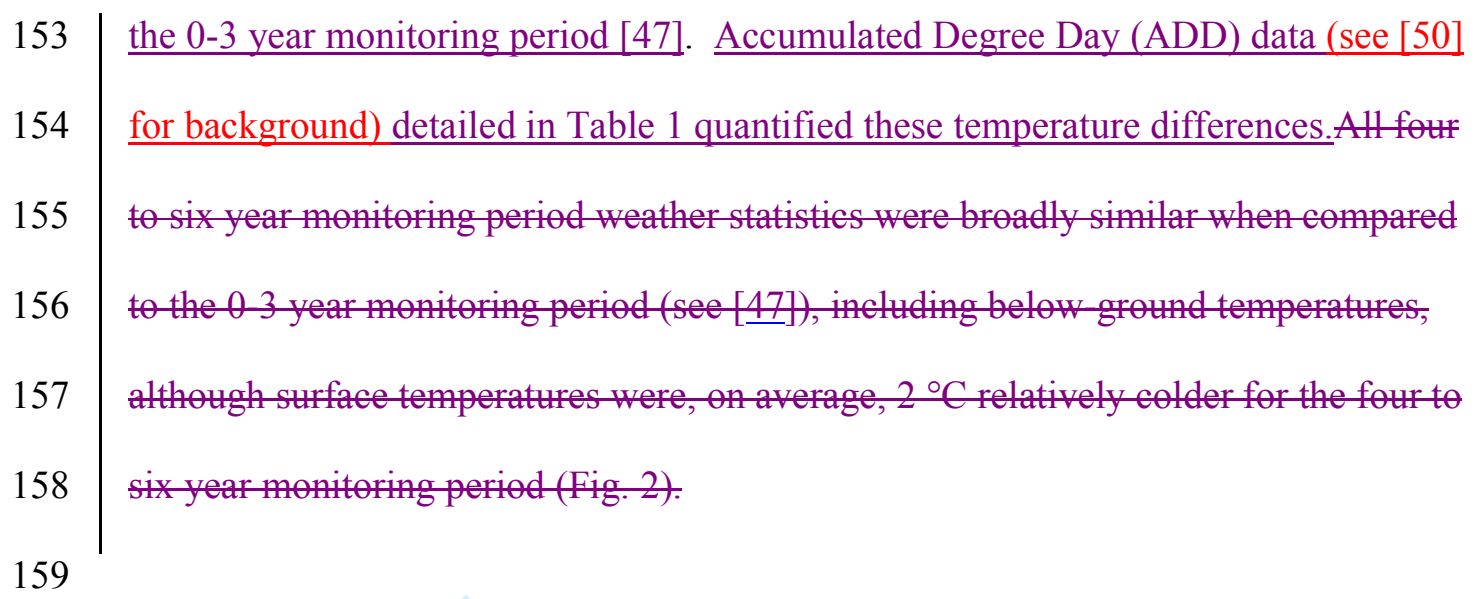

160 FIG. 1. -position

161

162

FIG. 2. -position

163

164

Simulated graves

165

166 Five simulated graves were created at the site (Fig. 1A). Three of the graves were

167 used for the repeat geophysical surveys, whilst ground water samples were collected

168 at regular intervals from both the fourth grave and a separate control site situated $\sim 10$

$169 \mathrm{~m}$ upslope away from the graves (Fig. 1E-F), both of the soilwater sampling sites

170 being outside the geophysical survey area (Fig. 1A). Of the three simulated graves

171 geophysically surveyed, one contained a naked pig carcass, one contained a wrapped

172 carcass wrapped in woven PVC tarpaulin and the third was an empty grave to act as a

173 control (Fig. 1). Pig cadavers are commonly used in such monitoring experiments as

174 they comprise similar chemical compositions, size, tissue:body fat ratios and skin/hair

175 type to humans [1, 52]. The grave emplacement procedure was described in [47]. 176

177 Bulk ground water conductivity data collection 
178

179 Ground water sample lysimeters were emplaced both within a grave containing a pig

180 carcass outside the geophysical survey area and a further lysimeter $\sim 10 \mathrm{~m}$ from the

181 survey area to act as control (Fig. 1). The lysimeter emplacement and regular sample

182 collection (Table 1) and analysis procedures used in this study were the same as for

183 the initial three year monitoring period and are described in [47]. The only change

184 was the sample frequency with samples collected at approximately three-monthly

185 seasonal intervals during the four to six year monitoring period due to limited monthly

186 changes observed in the zero to three year monitoring period [47] and survey time

187 constraints (Table 1).

188

189 TABLE 1.

190

191 Near surface geophysical data collection \& processing

192

193 Fixed-offset Twin electrode (0.5 m fixed-offset) resistivity surveys were conducted at

194 three monthly intervals over the geophysical survey area (Fig. 1A-B) during the four

195 to six year monitoring period (Table 1). Data was collectedion using the RM15

196 (Geoscan ${ }^{\mathrm{TM}}$ Research) resistivity meter on a $0.25 \mathrm{~m}$ by $0.25 \mathrm{~m}$ grid with remote

197 probes placed on the same position $17 \mathrm{~m}$ from the survey area for consistency. and

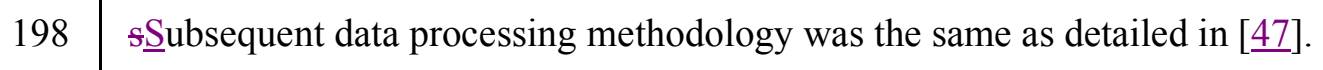

199

200 A 2D Electrical Resistivity Imaging (ERI) survey line orientated SW-NE (Fig. 1A-B)

201 was surveyed at approximately three-monthly intervals (Table 1). 32 electrodes were

202 placed every $0.5 \mathrm{~m}$ along Tthe $15.5 \mathrm{~m}$ long survey profile was $15.5 \mathrm{~m}$ long and that 
203 bisected all three graves (Fig. 1A). Geophysical survey collection using a Campus ${ }^{\mathrm{TM}}$

204 TIGRE system and subsequent inversion using Geotomo ${ }^{\text {TM }}$ Res2Dinv v.355 software

205 used in this study were the same as for the initial three year monitoring period and are

206 described in [47].

207

208 Due to the variable results of horizontal time slices that GPR data generated in the 209 zero to three year monitoring survey period (see [47]), 2D GPR profiles were only

210 collected on two profiles within the survey area that bisected the two simulated graves

211 with pigs present (Fig. 1A) at approximately three-monthly intervals (Table 1). GPR

212 data collection using the PulseEKKO ${ }^{\text {TM }} 1000$ equipment utilised $110 \mathrm{MHz}, 225 \mathrm{MHz}$,

$213450 \mathrm{MHz}$ and $900 \mathrm{MHz}$ dominant frequency antennae, with radar trace spacings being

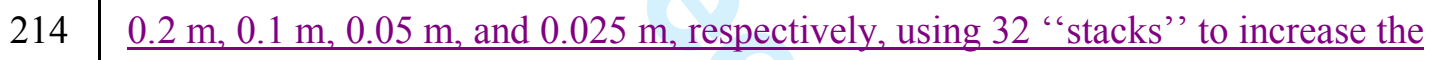

215 signal-to-noise ratio and for all data sets for consistency purposes. and s Subsequent

216 data processing were the same as for the initial three year monitoring period and are

217 described in [47], except for migration and the horizontal time slices not being

218 generated.

220 
222

223

224

225

226

227

228

229

230

231

232

233

234

235

236

237

238

242

244

245

Table 1 qualitatively summarises the respective geophysical anomaly visibilities in survey results based on [42] methodology of: None, Poor, Good and Excellent. A score of None indicated the respective grave was not detected, with a score of Poor showed a slightly discernible geophysical anomaly at the grave location. A score of

Good demonstrates a clear geophysical anomaly that would be discernible in the field during a geophysical survey and a score of Excellent demonstrates a clearly discernible and prominent anomaly at the grave location.

\section{Bulk ground water conductivity}

Background soilwater conductivity measurements demonstrated that background values were consistent over the three year monitoring period (averaging $355 \pm 0.1$ $\mu \mathrm{S} / \mathrm{cm}$ with $40 \mathrm{SD}$ ) that was comparable to the zero to three year monitoring period (averaging $444 \pm 0.1 \mu \mathrm{S} / \mathrm{cm}$ ). However, the pig leachate conductivity continued to reduce during year four (Fig. 3A), varying from $6,670 \pm 0.1 \mu \mathrm{S} / \mathrm{cm}(1,099$ days after burial) down to consistent and comparable background values of $356 \pm 0.1 \mu \mathrm{S} / \mathrm{cm}$ after 1,670 days of burial to the end of the monitoring period. Pig leachate conductivity changes during the first three years of burial are reported in [47]. Leachate values in this study could be grouped-divided into two clear linear-groupings regressions-of conductivity against post-burial days; 840-1,670 burial days (which included some data from the third year of monitoring) and 1,670 burial days to the end of the survey period respectively (Fig. 3A). The first data grouping had a

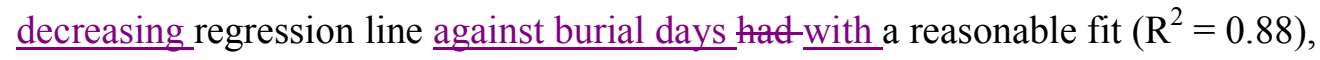


246 but with the correlation for the-second data grouping having a flat regression line,

247 albeit with a relatively poor correlation $\left(\mathrm{R}^{2}=0.47\right)$ due to its flat nature, evidencing

248 that pig leachate conductivity was consistently at background soilwater values line was much lower $\left(\mathrm{R}^{z}=0.48\right)$, see(Fig. 3A).

\section{FIG. 3. - position}

252

253 Site temperature variation could be removed from raw conductivity values as

254 discussed in [47 Pringle et al. 2012 jfs] by weighting each day by its average daily

255 temperature and then giving each day after burial an accumulated degree day (ADD)

256 following standard methods [50]. This study still had the advantage of having

257 temperature probe measurement data available from the actual mid-cadaver depth

$258(\sim 0.3 \mathrm{~m} \mathrm{bgl})$ from the nearby meteorological weather station, instead of using average

259 air temperatures (Fig. 2). This again allowed the generation-separation of two data

260 groupings with two linear regression correlations to be generated of conductivity

261 against $\mathrm{ADD}_{2}$ with similar fits to those generated against post-burial days $\left(\mathrm{R}^{2}\right.$ values

262 of 0.86 and 0.57 respectively), see Fig. 3B.

\section{Twin electrode Bulk ground-(fixed-offset) resistivity}

266 Bulk ground resistivity surveys acquired over the four to six year monitoring study

267 period were again remarkably consistent, with average fixed-offset survey resistance

268 values of $63.6 \Omega$ (with $47.0 \Omega$ minimum and $99.4 \Omega$ maximum values respectively)

269 (compared to an average of $67.1 \Omega$ for zero to three years), afterence de-spiking data

270 processing had been undertaken (only averaged 1.6 anomalous 'spike' per survey). 
271 The three monthly processed fixed-offset resistivity surveys are graphically shown in

272 Figure 4 (see Fig. 1A for 'grave' locations) and summarised in Table 1.

273

274 As found in the zero to three year monitoring datasets, the empty grave which acted as

275 control could not be geophysically detected throughout the survey period (green boxes

276 in Fig. 4). The naked pig grave (red boxes in Fig. 4) was anomalously temporally

277 variable throughout the four to six year monitoring period, mostly comprising a small

$278 \quad\left(<0.6 \mathrm{~m}^{2} \mathrm{SD}\right)$ amplitude mixed low/high anomaly, when compared to background

279 values (Fig. 4 and Table 1). It only comprised a large low anomaly with a low

280 resistivity (coloured blue) in the winter Year 4 dataset that was consistently observed

281 in the zero to three year monitoring datasets (see [40] and Table 1). In contrast, tThe

282 wrapped pig grave (blue boxes in Fig. 4) showed predominantly a large $\left(>0.6 \mathrm{~m}^{2} \mathrm{SD}\right)$

283 amplitude high resistivity anomaly (coloured red/white), when compared to

284 background values, that was mostly Good to Excellent rating and appeared to have

285 increased in size from the zero to three year monitoring dataset immediately after

286 burial (see [47] and Table 1).

287

288 FIG. 4. - position

289

290 Electrical resistivity imaging (ERI)

291

292 After de-spiking data, eElectrical resistivity imaging surveys acquired over the four

293 to six year monitoring study period were also again consistent, with average ERI six

294 'n' level survey resistivity values of $197.0 \Omega$.m with $106.0 \Omega$.m minimum and 318.9

$295 \Omega . m$ maximum respectively (compared to an average of $161.8 \Omega$ for zero to three 
296

297

298

299

300

301

302

303

304

305

306

307

308

309

310

311

312

313

314

315

316

317

318

319

years), once de-spiking data processing had been undertaken. A summary of the 2D

ERI profiles collected is graphically shown in Figure 5 (see Fig. 1A for profile

location) and summarised in Table 1. An average inversion model error (RMS) of 2.1

(with 1.2 minimum and 5.1 maximum) after five iterations again indicated a very

good model inversion fit to the collected resistivity values (compared to a RMS of

2.82 for zero to three years),

The empty grave (marked in Fig. 5) again could be detected throughout the survey

period, although, in contrast to the zero to three year monitoring period, it had

consistently higher resistivity values, when compared to neighbouring regions (Fig.

5). The naked pig grave was again generally detectable as a consistent Good rated

anomalous low, when compared to background values up to the end of year five,

although thereafter it was difficult to resolve from neighbouring regions (Fig. 5 and

Table 1). The wrapped pig grave was mostly surprisingly detectable as a large high

Good rated resistivity anomaly, when compared to background values, although the

$\underline{\text { anomaly }}$ it was relatively smaller in the summer and autumn of year's four and five

(Fig. 5). In the zero to three year monitoring survey the high resistivity anomaly was

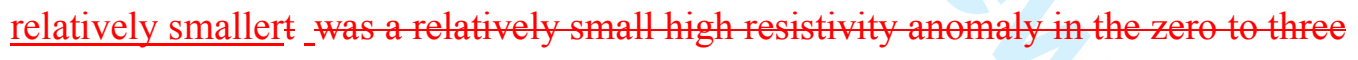

year monitoring survey period (see [4] and Table 1).

FIG. 5. - position 
320 The 2D GPR profiles acquired throughout the four to six year monitoring survey

321

322

323

324

325

326

327

328

330

331

332

334

335

336

337

338

339

340

341

342

343 period are shown in Figure 6A and 6B (see Fig. 1A for profile locations) and

summarised in Table 1. The $110 \mathrm{MHz}$ dominant frequency 2D profiles showed the

wrapped pig grave could still be consistently and clearly identified by a strong $\underline{\text { Good }}$

to Excellent rated hyperbola throughout the survey period (except for year 5 summer),

although there was a continual reduction in reflection amplitudes. This was in

contrast to the naked pig grave which was either barely to not detectable or at best

produced as a Poor rated hyperbola throughout theis survey period (see Fig.6A and

$6 \mathrm{~B}$ and Table 1). There were no clear hyperbolae other than those associated with the target graves within these $2 \mathrm{D}$ profiles.

The $225 \mathrm{MHz}$ dominant frequency 2D profiles still showed the wrapped pig grave could be clearly identified by an obvious Good to Excellent rated hyperbola throughout the four to six year monitoring survey period, although there was also a continual reduction in reflection amplitudes (see Fig.6A and 6B). The second, slightly deeper reflector that was first resolved after 15 months of burial within the wrapped pig grave (see [47]) was still present in this dataset. The naked pig grave was difficult given a Poor to None rating of to detect as a hyperbola anomaly throughout the four to six year monitoring survey period although it was possible tojust detectable in the autumn and winter data of year 4 (Fig. 6A/B). As per the zero to three year monitoring survey results [47], there were other, smaller hyperbolae present in the naked pig profiles that were not associated with the target. This s which would have made it difficult to identify the target grave if the position was not known. However, note they may have been detected if data were collected orthogonally to the 
344 primary survey line orientation or indeed if time slices were generated (although the zero to three year survey time slice data detailed in [47] was poor).

347 The $450 \mathrm{MHz}$ dominant frequency 2D profiles showed the wrapped pig grave could

348 be identified by a Good to Excellent rated hyperbola throughout the four to six year

349 monitoring survey period, but this had a consistently low amplitude (see Fig.6A and

350 6B and Table 1). The second, slightly deeper hyperbola observed after 3 months of

351 burial was still present during this survey period. The naked pig grave was rated as

352 Poor to None rated detectable as a hyperbola throughout the four to six year

353 monitoring period. There were again numerous other, smaller hyperbolae present in

354 both profiles that were not associated with the target grave which would have made it

355 difficult to identify the target grave if the position was not known. These may, again

356 have been detected if data were collected orthogonally to the primary survey line

357 orientation or indeed if time slices were generated (although the zero to three year

358 survey time slice data detailed in [47] was again poor).

360 The $900 \mathrm{MHz}$ dominant frequency 2D profiles was rated Poor to None rated so was

361 difficult to could notidentify the naked pig grave throughout the four to six year

362 monitoring period (see Fig.6A and 6B). There were numerous other, smaller

363 hyperbolae present which would also have made it difficult to locate the target grave 364 although orthogonal surveys may have been successful. 365

366 FIG. 6(A).

367

368 FIG. 6(B). 
369

370

371

372

373

374

375

376

377

378

380

381

382

383

384

385

386

388

389

390

391

392

393

\section{Discussion}

This study is the first published research to systematically detail resistivity, GPR and site monitoring data over a simulated clandestine grave test site over six years of burial summarised in Table 1. Importantly both naked and wrapped cadavers have been emplaced and surveyed which provides the two main burial styles encountered in discovered clandestine graves of murder victims. This has allowed questions by forensic search teams listed in the introduction to be answered that has not been able to be undertaken to_date. These will be sequentially discussed and are deliberately similar to those posed in the zero to three year monitoring paper [47].

\section{Firstly, A) $\in$ Could twin electrode (fixed-offset) and electrical resistivity imaging} surveys still successfully locate the 'naked' and 'wrapped' simulated clandestine burials beyond three years after burial? And if so, how long were they geophysically detectable for? From the results of this long-term study, the answer was, it still depends on the burial style. The fixed-offset electrical resistivity surveys showed that a naked cadaver(s) has a good chance of being located up to 2.5 years after burial (see $\underline{\text { Table } 1 \text { and }}$ [47]), due to the highly conductive grave fluid' producing a consistent low resistance geophysical anomaly when compared to background site resistance values (Fig. 3). This agrees with other resistivity studies over simulated clandestine burials with similar monitoring time periods (see $[\underline{26}, \underline{52}]$. Recent collaborative research comparing the same monitoring experiment on three different University 
394 However, this study showed that a naked cadaver would be very difficult to detect

395 using fixed-offset electrical resistivity surveys after only four years of burial (Fig. 4)

396 and using ERI surveys after five years of burial (Fig. 5) respectively. The majority of

397 the grave fluids (other than that held by capillary pressure) would migrate away from

398 the cadaver and potentially result in a geophysical anomaly not being over the target,

399 and hence the subsequent search excavation team not finding the target, which would

400 be especially problematic in surveys within significant topographic variation (see

$401[1, \underline{30}]$. In contrast, the wrapped or clothed cadaver(s) essentially largely isolated the

402 target and its conductive grave fluids from the surrounding soil, giving a potential

403 barrier to electrical current. There was therefore a small and temporally varying high

404 resistance anomaly, with respect to background site resistance values, identified over

405 the wrapped target location in the zero to three year monitoring data (see [47]), the

406 varying nature suggested to be caused by some leaking of grave fluids into the

407 surrounding soil. However, this paper detailing the four to six year monitoring data

408 showed a consistent large high resistance anomaly, when compared to background

409 site resistance values, to be present in both the fixed-offset and ERI electrical

410 resistivity datasets over the wrapped cadaver (see Figs. 4 and 5), this consistency

411 presumably due to most grave fluid at this time period being largely absent from the

412 survey area. Note that wrapping a body in plastic or clothing has also been reported

413 by others to slow decomposition [ㅍ] ] and inhibit micro-organism activity [1] which

414 therefore suggests a clandestinely buried body may be identifiable for longer if

415 wrapped in woven PVC tarpaulin as compared to naked.

416

417 Using all the resistivity datasets collected in the six year monitoring period, a

418 graphical time-line diagram has been generated to show temporal resistivity anomaly 
419 variations (Fig. 7). In terms of optimally configuring fixed-offset resistivity

420 equipment if the likely depth of burial is unknown, modern versions (eg. the

421 Geoscan ${ }^{\mathrm{TM}} \mathrm{RM}-15$ used in this study) have the capability to collect and digitally

422 record fixed-offset resistivity data at a variety of probe spacings almost

423 simultaneously at each sampling position (see [54] for forensic resistivity dataset

424 examples). This would therefore not significantly add to survey time if more than one

425 probe spacing data is collected and trace sample spacing could still be comparatively

426 small so that any potential loss in resolution is minimised. The forensic resistivity

427 su\fvey results in this paper are in sandy loam soil, with good forensic resistivity

428 survey results also reported in coastal sand [36], chalky [26] and black earth [54] soil

429 types respectively, but relatively poor results in coarse pebble soil types [54].

431 FIG. 7. - position

432

433

Secondly, $\underline{B}$-ECould single profile GPR surveys successfully locate both simulated

clandestine burials throughout the four to six year monitoring period? And which

435 dominant frequency antenna was optimal to detect them? From the results shown in

436 this four to six year monitoring study, the naked cadaver was not able to be detected

437 on 2D GPR transverse profiles using either the $110 \mathrm{MHz}$ or $900 \mathrm{MHz}$ dominant

438 frequency antennae and was only poorly detectable by the $225 \mathrm{MHz}$ dominant

439 frequency antennae in the autumn to winter datasets (Fig. 6A/B). This was in contrast

440 to the zero to three year monitoring period [47] and other studies undertaken on [47]

441 timescale (e.g. see [38,39,42]). The naked cadaver, however, was detectable as a

442 deeper $1 / 2$ hyperbolic reflection event in the $450 \mathrm{MHz} 2 \mathrm{D}$ transverse profiles although

443 this did not have high amplitudes (Fig. 6A/B). In contrast, the wrapped cadaver was 
444 detectable on 2D GPR profiles using all the frequencies trialled, namely the 110,225

445 and $450 \mathrm{MHz}$ dominant frequency antennae (the $900 \mathrm{MHz}$ antennae was not used

446 over this grave, but it is believed that the grave could have been detected with this

447 frequency based on the other frequency data). This was presumably still due to the

448 wrapping surface allowing stronger GPR reflections to be obtained, with the

449 decomposing naked cadaver attenuating a greater proportion of the GPR signal as

450 other authors have noted (e.g. see [42]). This radar absorption would be exacerbated

451 by the pig-chest cavity having collapsed during decomposition stages as noted in [47],

452 which is a probable explanation for the two GPR hyperbolae still present in 225 and

$453450 \mathrm{MHz}$ dominant frequency data over the target location (Fig. 6A/B). $225 \mathrm{MHz}$

454 dominant frequency antennae was shown in this study to be preferable to the other

455 frequencies trialled $(110,450$ and $900 \mathrm{MHz}$ frequencies $)$ in the $2 \mathrm{D}$ profiles due to a

456 detectable anomaly, target resolution and fewer non-target hyperbolae present in the

457 relative higher frequency data; note also forensic $225 \mathrm{MHz}$ frequency radar surveys

458 also took less time in the field to acquire when compared to their higher frequency

459 versions. This could be an important factor for a forensic search team to consider if

460 the proposed area is significant in size or if manpower and/or budget are limited. This

461 agrees with others (e.g. [42]) who also suggested that 2D GPR profiles should be

462 collected in both orientations over a survey site if possible to have the best chance of

463 detection.

464

465 C) Thirdly, when was the optimal time (both up to six years post-burial and

466 seasonally) to undertake a forensic GPR or electrical resistivity geophysical search

467 survey? Clearly from the results shown in this study and others (e.g. [42]) the burial

468 style is key, it would be difficult to detect a naked burial after the first 18 months of 
469

470

471

472

473

474

475

476

477

478

479

480

481

482

483

484

485

486

487

488

489

490

491

492

493

burial using the resistivity and GPR survey methods detailed here and in [47].

However, note that other studies have shown favourable GPR survey results over

much older burials in different ground conditions (eg. ([3,34,54,55]). Using [37

Schultz \& Martin 2012] four-fold method for qualitatively determining a hyperbola

anomaly response over a simulated burial, i.e. excellent, good, poor and none, Figure

8 graphically summarises this for the (A) wrapped and (B) naked cadaver

respectively. Whilst there is a general reduction in hyperbola quality in both burial styles, with the naked cadaver being much more difficult to detect, there is a seasonal effect, with autumn and winter surveys, especially in years four to six post burial, generally better at resolving the targets. This has also been observed by authors geophysically monitoring simulated clandestine burials on shorter time scales (e.g. [42]).

The resistivity surveys also showed a similar pattern, especially the fixed-offset electrical resistivity surveys which, when following [46] methodology to numerically measure resistivity anomaly relative areas over time, consistently showed winter surveys were optimal (Fig. 9Table 1). Each autumn to winter the anomalies over both the naked and wrapped cadavers increased in area and reduced in normalised standard deviation (SD) values whereas they were comparably smaller and had larger SD values in the summer months (Fig. $\underline{8}$ ). The naked cadaver's anomaly and the normalised SD of the datasets got progressively smaller over time, but the wrapped cadaver's relatively high resistance anomaly increased in size over the six year study period (Fig. ). Temporally varying resistivity anomalies over fixed archaeological targets have also been reported by [56] who undertook time-lapse resistivity surveys over UK Roman fortification defence ditches. This study therefore shows the cyclical 
494 nature of low winter/spring SD values and high summer/autumn SD values repeating

495 each year that was most probably due to the soil having reduced moisture content

496 during the warmer and dryer periods but, importantly, in a non-uniform manner for

497 this study site. Thus the 'noise' present within the geophysical data significantly

498 increased during these seasonal periods and effectively 'masked' the target(s). See

499 ([52] and [57] for detailed analysis of site soil moisture for the first two years of 500 burial.

501

502 FIG. 8. - position

503

504 D) When should a forensic geophysical survey be undertaken in a six year 505 search scenario? From this and other studiesy (e.g. 38-42,441), clearly the burial 506 style is still key; although the wrapped grave was initially harder to detect with

507 electrical resistivity surveys (as shown in [47]), in this paper it is relatively easier to 508 detect after four to six years of burial (Fig. 7). The wrapping also makes the target

509 easier to find with GPR as the wrapping makes a good reflective target (Table 1). So

510 although wrapping may help to conceal a body in some ways (for example, it may

511 trap scent and prevent decompositional fluids leaching into the soil), it may also make

512 a body easier to find geophysically. If the burial style is not known, then it is

513 suggested that both electrical and GPR surveys be undertaken to have the best chance

514 of successful detection. Note a naked cadaver would be progressively more difficult

515 to find after 18 months of burial as shown in this (Table 1) and other studies (see [38-

516 42,44]Figs. 8 and 9), and therefore other complementary methods should be trialled

517 (e.g. search cadaver dogs).

518 
519 This study also shows-reinforces other research (see e.g. 38-42,44,56]) the importance

520 of when a forensic geophysical survey should be conducted within the year,

521 seasonality has shown to be surprisingly important, and, if operational time permits,

522 then geophysical surveys should be undertaken in winter to have the best chance of

523 target detection success. If a past forensic geophysical search was unsuccessful,

524 perhaps the results should be reviewed in terms of seasonality and perhaps re-

525 surveyed if the original survey season was unfavourable. If there is a time-restricted

526 element to the forensic search, then the season of surveying should be undertaken and

527 an appropriate alternative search method should be chosen if necessary.

528

529 From this long-term simulated grave monitoring study and comparing results from

$530[\underline{24}, \underline{27}], \underline{29}, \underline{38-42,44,57-60]}$, we still recommend that forensic geophysical surveys

531 should be undertaken prior to other, more invasive search methods (e.g. metal

532 detectors, soil/methane probes and cadaver dog probes). Any resulting soil

533 disturbances from these surveys would lead to more false positives for the resulting

534 geophysical surveys, as found during the [29] forensic resistivity search. Once

535 anomalous geophysical areas within the survey area are identified, these should be

536 prioritised and then subjected to more detailed scientific investigations, which

537 includes geophysical surveys (e.g. 2D ERI profiles, higher frequency 2D/3D GPR

538 surveys), cadaver dogs, invasive probing, etc. See [11] for other geoscience search

539 methods and suggested phased investigative approaches.

540

541 


\section{Conclusions and further work}

543

544 Geophysical long-term monitoring survey results over the simulated clandestine

545 burials shown in this study and by others in different soil types should be used both to

546 assist forensic search investigators to use the appropriate search technique and

547 equipment configuration, and indeed as a reference to allow comparison of data

548 collected by forensic search investigators looking for similar clandestine burials of

549 murder victims.

550

551 A buried 'naked' victim within a clandestine burial, if shallowly buried, should be

552 able to be located within the first 4 years of burial using fixed offsettwin electrode

553 electrical resistivity surveys. If the burial depth is unknown, the use of wider

554 electrode separations in addition to the standard-most frequently used $0.5 \mathrm{~m}$ spacing is

555 recommended. Resistivity surveys are also recommended to be undertaken in clay-

556 rich soils over GPR surveys due to the likelihood of highly conductive 'leachate'

557 being retained in the surrounding soil and GPR experiencing poor penetration depths

558 in these soil types. However after this time period a naked victim would become

559 progressively more difficult to locate using electrical methods, with the majority of

560 the decompositional fluids migrating away from the target, depending upon the soil

561 type. However, ERI 2D profiles could potentially still locate naked victims up to five

562 years of burial if sited over it. $110-225 \mathrm{MHz}$ dominant frequency GPR surveys

563 could detect it targets well up to 18 months of burial, then $225 \mathrm{MHz}$ frequency poorly

564 in winter months up to five years of burial due to decomposition, although skeletal

565 material may still be imaged depending on target(s) depth and specific site conditions.

566 If time and manpower availability permits then winter surveys should be undertaken. 
568 A buried 'wrapped' or clothed victim within a clandestine burial, if shallowly buried,

569 should be able to be located using both fixed-offset electrical resistivity and ERI 2D

570 Profile surveys throughout the six year monitoring period; in fact in this study it

571 became progressively easier to detect the wrapped cadaver as the burial period

572 extended. Medium (225-450 MHz) dominant frequency GPR antennae were deemed

573 optimal frequency for detection due to good target resolution as other authors have

574 evidenced (e.g. [41-42]); less non-target anomalies and data acquisition speed,

575 although $110 \mathrm{MHz}$ and $450 \mathrm{MHz}$ frequency antennae data also resolved the wrapped

576 grave throughout the study period, most probably due to the 'wrapping' producing a

577 good reflective contrast. If time and manpower availability permits then winter

578 surveys should be undertaken.

579

580 This study site will be continued to be monitored annually to discover at what time

581 period after burial will geophysical surveys not be able to determine the location of a

582 clandestine burial. Organic, inorganic and other analytical measurements are

583 currently being undertaken to examine what may be causing the variability in grave

584 'soilwater' conductivity after burial with preliminary results looking promising [61]. 585

586 Further analysis of the geophysical data will also be undertaken; both to determine if

587 there are diagnostic GPR signal spectra for clandestine burials versus background

588 signals and to determine if both GPR and resistivity datasets can be simultaneously

589 inverted numerically to quantify anomaly location(s), sizes and to quantitatively

590 combine these two geophysical search techniques.

591 
592 This experimental methodology should be repeated on similar time scale in other,

593 contrasting soil types, in order to determine if soil type is a major factor in the ability

594 of forensic geophysical surveys to successfully locate a clandestine burial. On a

595 longer time scale, it is planned that the experiment will be repeated using human

596 cadavers rather than pig analogues, as this may be an important variable to consider.

597

598 
599 Acknowledgements

600

601 We acknowledge ex-Keele PhD student Tim Millington and Keele University

602 technical staff Malcolm Wright for assistance in creating the study site and Ian

603 Wilshaw for assistance in installing the lysimeters and providing local weather data.

604 Numerous Keele University undergraduate and postgraduate students assisted in

605 collecting geophysical data during this study, together with Giulia di Mascio from

606 Polimi University, Italy. Colin Hope of the U.K. National Crime Agency (NCA) is

607 thanked for operational search advice.

608 
609 References:

610

611 1. Harrison M, Donnelly LJ. Locating concealed homicide victims: developing the

612 role of geoforensics. In: Ritz K, Dawson L, Miller D, editors. Criminal and

613 Environmental Soil Forensics, Dordrecht: Springer, 2009;197-219.

614

615 2. Larson DO, Vass A A, Wise M. Advanced scientific methods and procedures in the

616 forensic investigation of clandestine graves. J Contemp Crim Justice 27 2011;27:149-

$617 \quad 82$.

618

619 3. Davenport GC. Remote sensing applications in forensic investigations. Hist Arch $620 \quad 2001 ; 35: 87-100$.

621

622 4. Killam EW. The detection of human remains. Springfield: Charles C Thomas, 6232004.

624

625 5. Dupras TL, Schultz JJ, Wheeler SM, Williams LJ. Forensic recovery of human

626 remains: archaeological approaches. 2nd ed, Boca Raton, FL: CRC Press, 2011.

627

628 6. Rebmann A, David E, Sorg MH. Cadaver dog handbook: forensic training and

629 tactics for the recovery of human remains. Boca Raton:CRC Press, 2000.

630 
\begin{tabular}{l|l}
631 & 7. Lasseter A, Jacobi KP, Farley R, Hensel L. Cadaver dog and handler team \\
632 capabilities in the recovery of buried human remains in the Southeastern United
\end{tabular}

633 States. J For Sci 2003;48:1-5.

634

635 8. Pye K, Croft, DJ. Forensic Geoscience: Principles, Techniques and Applications.

636 London: Geol Soc London Spec Pub 232, 2004.

637

638 9. Ruffell A, McKinley J. Forensic geoscience: applications of geology,

639 geomorphology and geophysics to criminal investigations. Earth Sci Rev

$640 \quad 2005 ; 69: 235-47$.

641

642 10. Ruffell A, McKinley J. Geoforensics. Chichester: Wiley, 2008.

643

644 11. Pringle JK, Ruffell A, Jervis JR, Donnelly L, McKinley J, Hansen J, Morgan R,

645 Pirrie D, Harrison M. The use of geoscience methods for terrestrial forensic searches.

646 Earth Sci Rev 2012a ; 114:108-23.

647

648 12. Davenport GC, Griffin TJ, Lindemann JW, Heimmer D. Geoscientists and law

649 enforcement officers work together in Colorado. Geotimes 1990;35:13-5.

650

651 13. Brilis GM, Gerlach CL, van Waasbergen RJ. Remote sensing tools assist in

652 environmental forensics. Part I. Digital tools - traditional methods. Env For

$6532000 \mathrm{a} ; 1: 63-7$.

654 
655 14. Brilis GM, van Waasbergen RJ, Stokely PM, Gerlach CL. Remote sensing tools

656 assist in environmental forensics. Part II. Digital tools. Env For 2000b;1:1-7.

657

658 15. Hunter J, Cox M. Forensic archaeology: advances in theory and practice.

659 Abingdon: Routledge, 2005.

660

661 16. Dickinson DJ. The aerial use of an infrared camera in a police search for the body

662 of a missing person in New Zealand. J For Sci Soc 1976;16:205-11.

663

664 17. Ruffell A, McKinley J. Forensic geomorphology. Geomorph 2014;206:14-22.

665

666 18. Owsley DW. Techniques for locating burials, with emphasis on the probe. J For

667 Sci 1995;40;735-40.

668

669 19. Ruffell A. Burial location using cheap and reliable quantitative probe

670 measurements. For Sci Int 2005a;151:207-11.

671

672 20. Hunter J, Simpson B, Sturdy Colls C, Forensic approaches to buried remains

673 (essential forensic science). Chichester: Wiley, 2013.

674

675 21. Reynolds JM. An introduction to applied and environmental geophysics, 2nd ed,

676 Chichester: Wiley-Blackwell, 2011.

677

678 22. Mellet JS. Location of human remains with ground penetrating radar. In:

679 Hanninen, P, Autio S, editors. Proceedings of the Fourth International Conference on 
680 Ground Penetrating RadarGPR, 1992 Jun 8-13; Rovaniemi, Geological Survey of

681 Finland Special Paper 16;359-65.

682

683 23. Calkin SF, Allen RP, Harriman MP. Buried in the basement - geophysics role in a

684 forensic investigation. Proceedings of the-sympesium on the application-Applof

685 Geophysies to enginEngeering and-environmental problems; 1995, Denver: Env Eng

686 Geophys Soc;397-403.

687

688

690

691 692

693

$694 \quad 2004 ; 232: 33-8$.

695

696

698

699

700

701

702

703

704
27. Ruffell A. Searching for the IRA “disappeared”: Ground Penetrating radar investigation of a churchyard burial site. J For Sci 2005;50:1430-5.

28. Schultz JJ. Using ground-penetrating radar to locate clandestine graves of

homicide victims: forming forensic archaeology partnerships with law enforcement.

24. Nobes DC. The search for "Yvonne": a case example of the delineation of a grave using near-surface geophysical methods. J For Sci 2000;45:715-21.

25. Scott J, Hunter JR. Environmental influences on resistivity mapping for the location of clandestine graves. In: Pye K, Croft DJ, editors. Forensic Geoscience:

Principles, Techniques and Applications. London: Geol Soc London Spec Pub

26. Cheetham P. Forensic geophysical survey. In: Hunter J, Cox M, editors. Forensic Archaeology: Advances in Theory and Practice, Abingdon: Routledge, 2005;62-95.

\section{$\underline{\text { Homicide Studies 2007;11:15-29. }}$}


706 707

clandestine burial of a homicide victim, UK. For Sci Int 2010;202(1-3):e1-7.

708

709

710

711

712

713

714

715

716 717

718

719 720

721

722

723 724 725

726

727

728

729

29. Pringle JK, Jervis JR. Electrical resistivity survey to search for a recent

30. Novo A, Lorenzo H, Ria F, Solla M. 3D GPR in forensics: finding a clandestine grave in a mountainous environment. For Sci Int 2011;204:134-8.

31. Schultz JJ. The application of GPR for forensic grave detection. In: Dirkmaat DC, editors. A companion to forensic anthropology, Hoboken, NJ: Blackwell, 2012, p.85$\underline{100 .}$

32. Ruffell A, Pringle JK, Forbes S. Search protocols for hidden forensic objects beneath floors and within walls. For Sci Int 2014;237:137-45.

33. France DL, Griffin TJ. Swanburg JG, Lindemann JW, Davenport GC, Trammell V. et al. A multidisciplinary approach to the detection of clandestine graves. J For Sci 1992;37:1445-58.

34. Strongman KB. Forensic applications of ground penetrating radar. In: Pilon J, editor. Ground Penetrating Radar, Ottawa: Geological Survey of Canada Paper 90-4, $1992 ; 203-11$. 
730 36. Pringle JK, Holland C, Szkornik K, Harrison M. Establishing forensic search

731 methodologies and geophysical surveying for the detection of clandestine graves in

732 coastal beach environments. For Sci Int 2012;219:e29-e36.

733

734

37. Pringle JK, Wisniewski K, Giubertoni M, Cassidy NJ, Hansen JD, Linford NJ,

735

Daniels RM. The use of magnetic susceptibility as a forensic search tool. For Sci Int

736

$\underline{2015 a ; 246: 31-42 .}$

737

738

38. Schultz JJ, Collins ME, Falsetti AB. Sequential monitoring of burials containing

739 large pig cadavers using ground-penetrating radar. J For Sci 2006;51:607-16.

740

741

39. Schultz JJ. Sequential monitoring of burials containing small pig cadavers using 742 ground-penetrating radar. J For Sci 2008;53:279-87.

743

744

40. Pringle JK, Jervis J, Cassella JP, Cassidy NJ. Time-lapse geophysical

745

investigations over a simulated urban clandestine grave. J For Sci 2008;53:1405-17.

746

747

41. Schultz JJ, Martin MM. Controlled GPR grave research: Comparison of reflection 748 profiles between 500 and $250 \mathrm{MHz}$ antennae. For Sci Int 2011;209:64-9.

749

750

751

42. Schultz JJ, Martin MM. Monitoring controlled graves representing common burial scenarios with ground penetrating radar. J App Geophys 2012;83:74-89.

752

753 43. Schotmans EMJ, Fletcher JN, Denton J, Janaway RC, Wilson AS. Long-term

754 effects of hydrated lime and quicklime on the decay of human remains using pig 
755 cadavers as human body analogues: Field experiments. For Sci Int 2014a;238:141.e1-

756 e13.

757

758 44. Molina CM, Pringle JK, Saumett M, Hernandez O. Preliminary results of

759 sequential monitoring of simulated clandestine graves in Colombia, South America,

760 using ground penetrating radar and botany.-For Sci Int 2015;248:61-70.

761

762 45. Pringle JK, Cassella JP, Jervis JR, Williams A, Cross P, Cassidy NJ. Soilwater

763 conductivity analysis to date and locate clandestine graves of homicide victims. J For

764 Sci in press.

765

766 46. Jervis JR, Pringle JK. A study of the affect of seasonal climatic factors on the

767 electrical resistivity response of three experimental graves. J App Geophys

$768 \quad 2014 ; 108: 53-60$.

769

770

47. Pringle JK, Jervis JR, Hansen JD, Cassidy NJ, Jones GM, Cassella JP.

771 Geophysical monitoring of simulated clandestine graves using electrical and Ground

772 Penetrating Radar methods: 0-3 years. J For Sci 2012ㅁ; 57:1467-86.

773

774 48. Manhein MH. Decomposition rates of deliberate burials: a case study of

775 preservation. In: Haglund WD, Sorg MH, editors. Forensic taphonomy: the post-

776 mortem fate of human remains, Boca Raton, FL: CRC, 1996;469-81.

777

778 49. Peel MC, Finlayson BL, McMahon TA. Updated world map of the Köppen-

779 Geiger climate classification. Hydro Earth Sys Sci 2007;11:1633-44. 
780

781 50. Vass AA, Bass WM, Wolt JD, Foss JE, Ammons JT. Time since death

782 determinations of human cadavers using soil solution. J For Sci 1992;37:1236-53.

783

784 51. Carter DO, Tibbett M. Cadaver decomposition and soil: processes. In: Tibbett M, 785 Carter DO, editors. Soil Analysis in Forensic Taphonomy: Chemical and Biological

786 Effects of Buried Human Remains. Boca Raton: CRC Press, 2009;29-52.

787

788 52. Jervis JR, Pringle JK, Tuckwell GT. Time-lapse resistivity surveys over simulated 789 clandestine burials. For Sci Int 2009;192:7-13.

790

791 53. Rodriguez WC. Decomposition of buried and submerged bodies. In: Haglund

792 WD, Sorg MH, editors. Forensic Taphonomy: The Postmortem Fate of Human

793 Remains. Boca Raton: CRC Press, 1997;459-68.

794

795 54. Hansen JD, Pringle JK, Goodwin J. GPR and bulk ground resistivity surveys in

796 graveyards: locating unmarked burials in contrasting soil types. For Sci Int

$797 \quad 2014 ; 237:$ e14-e29.

798

799

55. Bevan BW. The search for graves. Geophysics 1991;56:1310-9.

800

801 56. Clark AJ. Seeing beneath the soil: prospecting methods in archaeology, 2nd rev.

802 ed. New York: Routledge, 1996.

803 
804

57. Jervis JR. The detection of clandestine graves using electrical resistivity surveys:

805 results from controlled experiments and a case study ( $\mathrm{PhD}$ dissertation). Keele: Keele

806 University, 2011.

807

808 58. Ellwood BB, Owsley DW, Ellwood SH, Mercado-Allinger PA. Search for the

809 grave of the hanged Texas gunfighter, William Preston Longley. Hist Arch

$810 \quad 1994 ; 28: 94-112$.

811

812

814 radar investigation, NW Ireland. J For Sci 2009;54:382-94.

815

816

817 Expl Geophys 2004;35:88-92.

818

819 61. Blom G, Davidson A, Pringle J, Williams A, Lamont A, Cassella JP. Chemical

820 markers for the detection of clandestine graves - development of a complimentary

821 technique for forensic geophysics? Recent Work in Arch Geophys and For Geosci:

822 Future Horizons Conf, Geol Soc London, 2-3 December, 2014.
823

824 
825 FIGURE CAPTIONS:

826

827 FIG. 1. (A) Map of survey area (dashed rectangle) with graves, L1/2 GPR and ERI

828 2D profile lines, lysimeter positions and UK location map all shown (inset). (B)

829 Study site, (C) naked pig grave, (D) wrapped pig grave, (E) pig lysimeter grave and

830 (F) soil fluid measurement photographs respectively. Modified from [47]. 831

832 FIG. 2. Summary of monthly study site statistics of total rainfall (bars) and average 833 temperature (line) data at $0.3 \mathrm{~m} \mathrm{bgl}$ (below ground level), measured over the four to 834 six year study period. Dashed average temperature line is for zero to three years 835 survey period [47] shown for comparison.

837 FIG. 3. (A) Measured pig leachate (diamonds) and background (triangles) soil-water 838 fluid conductivity values over the 6-year survey period; 4-6 years to the right of the 839 vertical dotted line. (B) Measured soil-water conductivity versus accumulated degree 840 day (ADD) plot produced from (A) by summing average daily $0.3 \mathrm{~m} \mathrm{bgl} \mathrm{after} \mathrm{burial}$ 841 temperatures (see text). Best-fit linear correlation formulae and confidence (R2) 842 values are also shown. Modified from [47].

844 FIG. 4. Fixed-offset processed electrical resistivity datasets for the four to six year 845 study period (year and season shown). Red, green and blue rectangles indicate 846 positions of naked pig, empty and wrapped pig graves respectively (see Fig. 1A). 847

848 FIG. 5. Individually inverted 2D Electrical Resistivity Imaging (ERI) Wenner array

849 (0.5 m spaced electrode) profiles for the four to six year study period (year and season 
850 shown); model inversion errors (RMS) for the fifth iterations are indicated. Positions

851 of naked pig, empty and wrapped pig graves are also shown (dashed lines). See Fig.

$8521 \mathrm{~A}(\mathrm{ERI} / \mathrm{ERI})$ for location.

853

854 FIG. 6(A). Key sequential processed 110, 225, 450 and $900 \mathrm{MHz}$ dominant

855 frequency GPR profiles for the four to six year study period $\underline{39-54 \text { post-burial }}$

856 months (year and season shown) that bisect the naked and wrapped pig graves

857 respectively (Fig. 1A for location).

858

859 FIG. 6(B). Key sequential processed 110, 225, 450 and $900 \mathrm{MHz}$ dominant

860 frequency GPR profiles for $57-72$ post-burial months the four to six year study

861 (year and season shown) that bisect the naked and wrapped pig graves

862 respectively (Fig. 1A for location).

863

864 FIG. 7. Summary qualitative analysis plot of resistivity data over the complete six

865 year survey period with this paper 4-6 year survey period to the right of the vertical

866 dashed lines (see key and text). Modified from [47].

867

868

869

870

vertical dashed line (see key and text).

871

872 FIG. 8. Summary quantitative analysis plots of fixed-offset resistivity data collected

873 over the complete six year survey period with this paper 4-6 year survey period to the

874 right of the vertical dashed line. (A) Standard deviations (SD) for each survey, note 
1

2

3

4

5

6

7

8

9

10

11

12

13

14

15

16

17

18

19

20

21

22

23

24

25

26

27

28

29

30

31

32

33

34

35

36

37

38

39

40

41

42

43

44

45

46

47

48

49

50

51

52

53

54

55

56

57

58

59

60

875 SD values are highest in late summer; residual volume analysis of (B) naked pig

876 cadaver and (C) wrapped pig cadaver (see text). Modified from [46].

877

878 
879 TABLE CAPTION:

880

881 TABLE 1. Summary of geophysical surveys and their respective geophysical

882 anomalies data collected detailed in this paperstudy (4-6 year results below horizontal

$883 \underline{\text { line). }}$. GPR surveys conducted the day after respective survey dates and groundwater

884 conductivity measurements collected the day before respective survey dates. ${ }^{+}$Burial

885 date was $7^{\text {th }}$ December 2007. *ADD date based on average daily site temperatures at

$886 \quad 0.3 \mathrm{~m} \mathrm{bgl}$ (see [47]).

887

888 
889

890 Additional Information and Reprint Requests:

891 Jamie K. Pringle, Ph.D.

892 School of Physical Sciences \& Geography,

893 William Smith Building,

894 Keele University,

895 Keele,

896 Staffordshire,

897 ST5 5BG,

898 U.K.

899 E-mail: j.k.pringle@keele.ac.uk

900 